\title{
"You Have to Count the Squares": Applying Knowledge in Pieces to Learning Rectangular Area
}

\author{
Andrew Izsák \\ Department of Mathematics Education \\ The University of Georgia
}

\begin{abstract}
This article extends and strengthens the knowledge in pieces perspective (diSessa, 1988,1993 ) by applying core components to analyze how 5th-grade students with computational knowledge of whole-number multiplication and connections between multiplication and discrete arrays constructed understandings of area and ways of using representations to solve area problems. The results complement past research by demonstrating that important components of the knowledge in pieces perspective are not tied to physics, more advanced mathematics, or the learning of older students. Furthermore, the study elaborates the perspective in a particular context by proposing knowledge for selecting attributes, using representations, and evaluating representations as analytic categories useful for highlighting some coordination and refinement processes that can arise when students learn to use external representations to solve problems. The results suggest, among other things, that explicitly identifying similarities and differences between students' past experiences using representations to solve problems and demands of new tasks can be central to successful instructional design.
\end{abstract}

This case study applies core components of an epistemological perspective referred to as knowledge in pieces (diSessa, 1988, 1993) to answer an instance of the following research question: How can students coordinate their understandings of problem situations with those of external representations when learning to solve problems? DiSessa developed the knowledge in pieces perspective to explain emerging expertise in Newtonian mechanics. The perspective holds that knowledge elements are more diverse and smaller in grain size than those presented in

Correspondence and requests for reprints should be sent to Andrew Izsák, Department of Mathematics Education, The University of Georgia, 105 Aderhold Hall, Athens, GA 30602-7124. E-mail: izsak@uga.edu 
textbooks. ${ }^{1}$ Growth and change consists of multiple, related processes including not only the construction of new knowledge elements, but also the coordination of diverse knowledge elements and the extension or constriction of conditions under which particular elements may be applied productively. Further research has applied the knowledge in pieces perspective to examine emerging competence in the domains of Newtonian mechanics (e.g., Roschelle, 1998; Sherin, 2001), intuitive epistemology (diSessa, Elby, \& Hammer, 2003; Hammer \& Elby, 2002), functions (e.g., Monk \& Nemirovsky, 1994; Moschovich, 1998), fractions (Smith, 1995), and probability (Wagner, 2003). Most participants in these studies have been high school and college students.

The study presented here extends and strengthens the knowledge in pieces perspective by applying core components to answer the following instance of the research question previously mentioned: How can elementary school students who have computational knowledge of whole-number multiplication and who have made connections between multiplication and discrete arrays construct understandings of area and ways of using representations to solve area problems? By providing an existence proof that the knowledge in pieces perspective can lend insight into learning core topics in elementary mathematics, the study presented here demonstrates that important components of the perspective are not tied to physics, more advanced mathematics, or the learning of older students. The study also elaborates the perspective in contexts where students are learning to use external representations to solve problems by proposing analytic categories for knowledge that highlight some coordination and refinement processes. Finally, past research has demonstrated that many students have trouble understanding the multiplicative relation between length and area measurement. Because students often bring experiences with whole-number multiplication and discrete representations to the study of area, understanding how the case study students used such prior knowledge to build understandings for representing and solving area problems can provide insight into the learning of still other students in this domain.

Smith, diSessa, and Roschelle (1993) restated key components of the knowledge in pieces perspective in their critique of misconceptions research. These authors claimed that understandings termed misconceptions in past research are, in fact, rooted in productive and effective knowledge imbedded among further cognitive structures that form knowledge systems. These authors restated knowledge refinement as a useful perspective for understanding the gradual transformation of novice into expert knowledge systems and pointed out that elements in such systems can take multiple forms, including conceptual, strategy, justification, and control knowledge (Smith et al., 1993, p. 148).

\footnotetext{
${ }^{1}$ In diSessa's analysis of physics, these elements have roots in people's day-to-day experiences interacting with the physical world.
} 
I examine several forms of knowledge that played a role in the gradual transformation of case study students' knowledge. Among other resources, I focus on students' criteria for representations, a class of knowledge that has emerged as a focus in recent research on metarepresentational competence (e.g., diSessa, 2002; diSessa, Hammer, Sherin, \& Kolpakowski, 1991; diSessa \& Sherin, 2000). Metarepresentational competence refers to cognitive resources for generating possibly new external representations and capabilities to judge and refine such representations. It also includes understanding how to work with representations for different purposes and can support students' ability to learn new representations and explain their properties. diSessa suggested that criteria are most likely to be engaged when students design representations, and most research on metarepresentational competence has focused on cases in which middle and high school students have designed graphical representations of motion and spatially distributed data. The study presented here demonstrates that students can engage criteria for representations when learning to use more schooled representations for different purposes, contributes to mathematics education research by uncovering constructive resources that have not previously been reported in studies of multiplication or area measurement, and addresses implications for instructional design in the concluding discussion.

\section{CHILDREN'S MATH WORLDS}

The study presented here was conducted in the context of current mathematics education reform efforts in the United States. In response to new standards for school mathematics (National Council of Teachers of Mathematics, 1989, 2000), recently developed mathematics curricula have often approached core topics through tasks that require students to coordinate understandings of problem situations, representations of those situations, and solution strategies. Several such curricula have been funded by the National Science Foundation (NSF; e.g., Coxford et al., 1998; Lappan, Fey, Fitzgerald, Friel, \& Phillips, 2002; The University of Chicago School Mathematics Project, 1995). This study was conducted in the context of a further NSF-funded curriculum development project called Children's Math Worlds to be published under the name of Math Expressions (CMW; Fuson, in press). A main objective of CMW is to make the goals of the new mathematics standards accessible, particularly to urban, as well as suburban, students and teachers.

The data for this article come from the CMW project's second cycle of developing and implementing multidigit multiplication materials. ${ }^{2}$ The materials intend for students to (a) coordinate multiplication, arrays, and rectangular areas and (b)

\footnotetext{
2Izsák (2004b) and Izsák and Fuson (2000) reported results from the first cycle of development and implementation.
} 
use their resulting understandings as the basis for constructing numeric methods for multidigit multiplication. The original intent for this study was to track interactions between classroom instruction and individual student learning by videotaping CMW lessons in one fifth-grade classroom and conducting weekly out-of-class interviews with a subset of students from the same class. The focus of the study shifted when, during the interviews, students grappled with several understandings that have not been reported widely in the multiplication or area measurement literatures. In addition to knowledge of whole-number factor-product combinations, connections between multiplication and repeated addition, and aspects of linear measurement, the students also engaged knowledge for using dots as representations of situations, associations with the words inside and outside, and the criterion that drawings be to scale. Investigating how students coordinated and refined such knowledge to construct understandings of area and ways of using representations to solve area problems required interviews that progressed through tasks more slowly than the lessons. Thus, resulting interviews did not pursue multidigit multiplication in much depth.

\section{RESEARCH ON WHOLE-NUMBER MULTIPLICATION, ARRAYS, AND RECTANGULAR AREAS}

Theoretical and empirical studies have examined connections among whole-number multiplication, arrays, and rectangular areas. Classifications of situations that can be modeled by multiplication have consistently included rectangular areas (e.g., Greer, 1992; Schmidt \& Weiser, 1995; Schwartz, 1988; Vergnaud, 1983, 1988), and research on multiplication has used rectangles to illustrate multiplication of fractions and the commutative property (Greer, 1992). Some researchers have suggested, however, that students connect multiplication to areas of rectangles by reciting, but not understanding, the length times width formula (De Corte, Verschaffel, \& Van Coillie, 1988; Nesher, 1992; Peled \& Nesher, 1988; Simon \& Blume, 1994).

Several multiplication studies have taken place in classrooms (e.g., Confrey \& Scarano, 1995; Hino, 2002; Izsák, 2004b; Lampert, 1986a, 1986b; Mechmandarov, 1987, as discussed by Nesher, 1988; Scarano \& Confrey, 1996; Treffers, 1987), but only those by Hino and by Izsák have had a primary focus on arrays and rectangular areas. Hino analyzed students' progressive uses for single-digit multiplication when determining areas in one Japanese fourth-grade classroom, but he did not focus in depth on students' connections between multiplication and the underlying row and column structure of unit squares. Izsák compared how taken-as-shared classroom practices (e.g., Cobb, Stephan, McClain, \& Gravemeijer, 2001) and individual students in one U.S. fourth-grade classroom used area representations to coordinate expanded forms for factors (e.g., $28=20+$ 
8) and the distributive property during the CMW project's first cycle of developing and implementing multidigit multiplication materials. These studies did not examine how students could construct understandings of rectangular areas as arrays of unit squares. The next sections summarize research on students' understandings of rectangular areas and cognitive resources for connecting multiplication and arrays that inform the study presented here.

\section{Students' Understandings of Rectangular Areas}

Research has suggested that a good understanding of linear measurement is prerequisite to a good understanding of area measurement and that linear and area measurement rely on many of the same ideas related to unit (Lehrer, 2003; Lehrer, Jenkins, \& Osana, 1998; Stephan \& Clements, 2003). These include (a) relations between the unit of measurement and the attribute being measured (e.g., Can you use length units to measure area?), (b) the need to iterate a fixed unit and the idea that a length or area can be partitioned into a number of equal-sized units, (c) unlike units (e.g., feet and inches) cannot be counted the same, (d) measurement units should cover or fill the attribute being measured without overlap, and (e) the size of the unit is inversely proportional to the measure of a quantity. Elementary school students do not appear to develop these ideas in a predictable order and can have a better grasp of some than others. These studies have demonstrated that a fully developed understanding of linear and area measurement requires the coordination of multiple ideas and that the process of coordination can vary from student to student. Moreover, Simon and Blume (1994) demonstrated that difficulties coordinating ideas related to linear and area measurement can persist well beyond elementary grades. They found that, in a group of 26 preservice teachers, many did not fully understand the multiplicative relation between linear and area measurements of rectangles. These researchers argued that most learners must use rectangular areas, understood as arrays of unit squares, as the basis for understanding the transformation of length into area measurements.

Other research has suggested that understanding rectangular areas as arrays of unit squares can be accessible to upper elementary students. Peled and Nesher (1988) found that fifth- and sixth-grade students had good understandings of the constraints that equal groups problems must satisfy, including situations where discrete objects are arranged in arrays. Students knew that each row in an array must have the same number of elements and that each column must have the same number of elements, but they could not connect rectangular areas to arrays or repeated addition when unit squares were not rendered. In subsequent research, Outhred and Mitchelmore (2000) examined how first- through fourth-grade students covered rectangles by drawing unit squares of a size specified in each of three tasks. Although none of the students had been taught area measurement, virtually all fourth-grade students generated correct coverings-arrays of unit 
squares with no gaps or overlaps. Having students draw instead of using physical tiles was a significant element of the research design because, by fitting together neatly, tiles make it possible for students to overlook the array structure and covering property (for further discussion, see Outhred \& Mitchelmore, 2000, p. 146). Battista, Clements, Arnoff, Battista, and Borrow (1998) suggested, however, that array structures are less accessible to early elementary students. These studies have evidenced that upper elementary students can understand rectangular areas in terms of rows and columns of unit squares, the conception that Simon and Blume (1994) argued was prerequisite to coordinating linear and area measurement. These same studies, however, have not examined in much detail how students could construct such a conception. The next section summarizes research on cognitive resources that students can use to construct understandings of whole-number multiplication, the array structure, and connections between the two.

\section{Counting and Repeated Addition as Resources for Connecting Multiplication and Arrays}

Whole-number multiplication is often introduced to students as repeated addition. Some researchers (Bell, Fischbein, \& Greer, 1984; Fischbein, Deri, Nello, \& Marino, 1985) argued that primitive psychological models for each arithmetic operation mediate students' selection of operations when solving problems and that repeated addition is the primitive model for multiplication. In other work (Bell, Greer, Grimison, \& Mangan, 1989; Nesher, 1988, 1992; Peled \& Nesher, 1988), researchers have challenged this position, arguing that experiences with language and school tasks affect the connections students make between the two operations. In further work, Anghileri (1989), Kouba (1989), and Mulligan and Mitchelmore (1997) analyzed how elementary school students used blocks and other manipulatives to solve single-digit problems about equal groups situations and, at the same time, develop understandings of whole-number operations. These researchers used large samples containing a cross section of students, primarily from first through third grade, to map students' increasingly efficient counting strategies that led to repeated addition and culminated in recalled multiplication facts. Anghileri accounted for the evolution of observed strategies in terms of automatization and reduced demands on working memory.

Although research discussed previously has often treated whole-number multiplication as an abbreviation of whole-number addition, several researchers (e.g., Clark \& Kamii, 1996; Confrey, 1994; Confrey \& Smith, 1994, 1995; Schwartz, 1988; Steffe, 1988, 1994; Vergnaud, 1983, 1988) argued that the psychological operations and types of quantities involved in multiplicative thinking are different than those involved in additive thinking. I discuss the work of Steffe because he has traced the development of individual third-grade students' psychological structures for multiplication out of their structures for counting and because other re- 
searchers have applied his results to study children's understanding of rectangular area.

Central to all of Steffe's $(1988,1994)$ work is the notion of a scheme. A scheme is a cognitive structure with three parts: (a) an assimilatory structure that activates when a child recognizes a relevant situation, (b) an activity or mental operation associated with situations that stimulate the assimilatory structure, and (c) an anticipated outcome or result of performing that activity or operation. Schemes support goal-directed activity by allowing a child to anticipate the result of an activity or operation before execution.

Steffe's analysis of emerging multiplication schemes relies on the notion of composite units. Children begin to form composite units through interiorization of mental records of counting. A child who has formed composite units can understand the number 5 simultaneously as one group of five and as five individual units. Through further interiorization of composite units, a child can understand the number 5 as both one group of five and five groups of a second composite unit. Steffe referred to this coordination of two composite units as a multiplying scheme. In fact, a child with such a scheme has coordinated three levels of units and, for example, could assimilate a display of 20 blocks as five composite units, each of which contains a second composite unit composed of four individual units. (The blocks might not have to be arranged in an array to stimulate the scheme.) A child could coordinate just two levels of units to solve addition problems, but must coordinate three levels of units to structure problems as ones involving multiplication. Thus, Steffe's developmental account emphasizes the interiorization of counting operations that make new types of units available, which, in turn, afford further changes in the assimilatory structure of children's counting schemes (see Steffe, 1988, 1994, for further details). In his studies, Steffe used tasks based on discrete manipulatives and did not examine the measurement ideas summarized previously.

Reynolds and Wheatley $(1996)$ extended Steffe's $(1988,1994)$ work by using composite units to explain how fourth-grade students could, or could not, generate rectangular coverings using the row and column structure of arrays. Students had paper, pencil, a ruler, and a calculator to answer the following question: "How many 3-by-5 cards are needed to cover a sheet of paper 12 by 30?" Data presented by Reynolds and Wheatley evidenced students' knowledge of measurement, as well as their available counting units and operations. One student, Kristen, appeared to understand that she could use either inches or centimeters to solve the problem so long as she used one measurement unit consistently. A second student, Tracy, mixed 12 in. with $30 \mathrm{~cm}$ and was not able to construct an array of $3 \times 5$ cards to measure her $12 \times 30$ rectangle. The researchers argued that Tracy had not assimilated the task in such a way that she anticipated measuring the $12 \times 30$ rectangle using the $3 \times 5$ card as the unit. These data suggested that, when drawing rectangles, students engaged understandings of measurement as well as understandings of composite units and counting schemes. 
To summarize, a significant body of theoretical and empirical research has examined connections among whole-number multiplication, arrays, and rectangular areas. Researchers have suggested that students often recite, but do not understand, the length times width formula and have suggested that understanding arrays of unit squares can serve as a basis for understanding the transformation of length into area measurements. Although past research has demonstrated that upper elementary students can understand rectangular areas in terms of rows and columns of unit squares and has identified a range of understandings that support rectangular areas - including understandings of linear measurement, arrays, coverings, and counting schemes - the same research has not examined in much detail how students could construct rectangular areas as arrays of unit squares that cover. The study presented here uses the knowledge in pieces perspective to analyze an instance of such construction.

\section{LEARNING TO SOLVE PROBLEMS WITH THE CMW MATERIALS}

The CMW materials used in the study presented here relied on whiteboards that had printed on them a $50 \times 100$ array of dots. The boards had additional blank space on the front and back. The CMW project introduced the boards in its second iteration of the multiplication unit to provide students opportunities to draw rectangles and thus make more visible potential conceptual difficulties. The intent of early tasks was for students to (a) use the array of dots as a scaffold for drawing rectangles and (b) focus on connections among single-digit multiplication, equal groups, and areas of rectangles understood as arrays of unit squares. Subsequent CMW tasks had students sketch rectangles in the blank space on their boards to prepare for multiplying larger numbers. Students were to understand these sketches as less detailed versions of rectangles that they had been drawing over dots. Concluding tasks had students construct numeric methods for multidigit multiplication using sketched rectangles. See Izsák (2001) for further details.

During interviews, students often found dots more salient than spaces between dots when working with rectangles drawn on the CMW dot boards. For example, students might interpret a $2 \times 3^{3}$ rectangle as a $3 \times 4$ array of dots. I refer to arrays based on dots as the dot perspective and arrays based on unit segments and squares as the space perspective. I use dimensions when referring to the number of rows and columns in an array and total when referring to the number of elements in an array. In the dot perspective, dimensions are numbers of dots across and down an array, and totals are total numbers of dots. In the space perspective, dimensions and

\footnotetext{
${ }^{3}$ Throughout the article, I express lengths of rectangles first and widths second: a $2 \times 3$ rectangle has two rows of three unit squares, and a $3 \times 2$ rectangle has three rows of two unit squares.
} 
totals correspond to normative dimensions and areas of rectangles. Students' juxtaposition of the dot and space perspectives was not intended by the CMW project, and their existing understandings of the dot perspective both supported and constrained their developing understandings of the space perspective.

Figure 1 summarizes analytic categories for students' knowledge that highlight coordination and refinement processes that emerged in the study presented here. Students evidenced knowledge that supported three subtasks - selecting attributes, using representations, and evaluating representations. The main case study illustrates how students refined knowledge used to select attributes. The arrows indicate that this refinement depended, in part, on coordination of knowledge for selecting attributes with knowledge for using and evaluating representations. The descriptions following anticipate key case study data and point out connections with prior research.

\section{Selecting Attributes}

For students with well-developed understandings of areas as coverings, the goal of determining area might focus attention quickly on unit squares. Moreover, a strong connection between areas and unit squares that cover might permit students to imagine arrays of unit squares on the CMW whiteboards even before drawing. As becomes clear during the analysis following, students in the case study presented here did not demonstrate a connection between areas and covering. Thus, they had to rely on other knowledge to guide their attention to particular collections of dots or spaces when answering questions about perimeters and areas of rectangles drawn on the boards. I discuss two key understandings that students evidenced.

First, students in the study presented here began with connections between perimeters and "outsides" and between areas and "insides" of rectangles. Although these connections gave some guidance, they were insufficient to direct students' attention toward appropriate unit segments for perimeters and unit squares for areas. For example, students tried using dots and unit segments to determine areas. Second, as students determined perimeters and areas of rectangles drawn on the dot boards, they became increasingly aware that numerical answers depended on the representa-

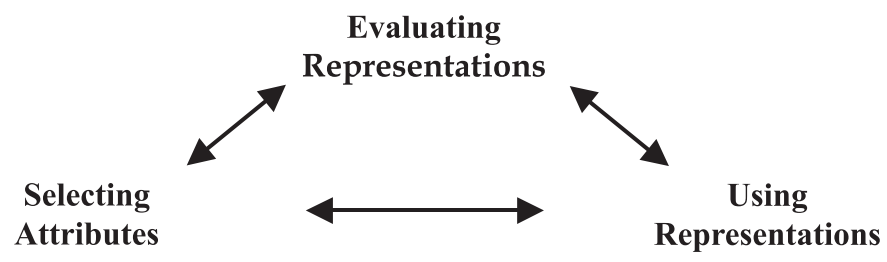

FIGURE 1 Theoretical frame that emerged from student interviews. 
tional feature used: Answers for the perimeter and area change when a $2 \times 3$ rectangle in the space perspective is viewed as a $3 \times 4$ array of dots. As students began to realize the consequences of using the dot or space perspective, they chose representational features more carefully when trying to accomplish a particular goal.

Previous research — but not research on multiplication and arrays - has examined cases where students attended to various features in a given situation or external representation and selected some over others as they attempted problem-solving goals. Izsák (2000) analyzed processes of notation variation and mapping variation that eighth-grade students used when constructing algebraic models of linear motions in a physical device, and Roschelle (1998) introduced registrations to characterize similar knowledge when analyzing students' qualitative reasoning about Newtonian motion simulated by a computer microworld. Other researchers (Lobato, Ellis, \& Muñoz, 2003; Lobato \& Siebert, 2002; Meira, 1995; Monk \& Nemirovsky, 1994; Moschkovich, 1998; Nemirovsky, 1994; Schoenfeld, Smith, \& Arcavi, 1993) also reported instances in which learning to focus on and use features of graphs and tables - including $y$-intercepts, $x$-intercepts, and slopes - and attributes of physical objects for solving problems has been a significant accomplishment for students.

\section{Using Representations}

Solving problems requires students to use selected attributes to accomplish goals, and multiple relations between attributes and goals can occur. In some cases, a given attribute can be used to accomplish a goal in more than one way. Students in the study presented here sometimes determined the total number of elements in an array by counting the elements one by one, other times by applying repeated addition to the number of elements in each row or column, and still other times by multiplying the dimensions. Understandings of the equal group structure and facility with computing sums versus products might determine which strategy a given student used. In other cases, more than one attribute can be used to accomplish a given goal. At different times, students used dots, unit segments, or unit squares to determine correct dimensions of rectangles. Shading in Figure 2 illustrates these three methods, and each can be extended to determine correct perimeters of rectangles. When counting unit squares to determine perimeters, students would have to count corner squares twice. ${ }^{4}$ The point is that unit segments are not the only representational feature that can be used to determine correct numeric values for dimensions and perimeters. Moreover, as research reviewed in the preceding paragraph has suggested, and as analysis following confirms, coordinating representational features with goals can be a significant, although often underemphasized, aspect of learning.

${ }^{4}$ During the study presented here, a student did determine correct perimeters in this way. 


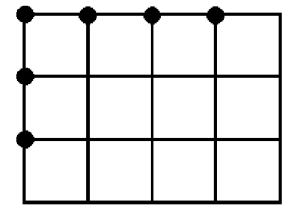

(a)

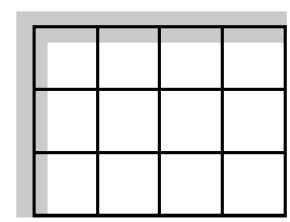

(b)

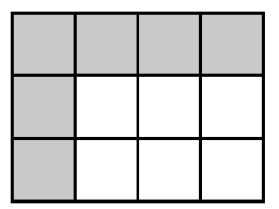

(c)

FIGURE 2 Three methods for determining dimensions of a $3 \times 4$ rectangle. (a) Counting 3 dots $\times 4$ dots. (b) Counting 3 unit segments $\times 4$ unit segments. (c) Counting 3 unit squares $\times 4$ unit squares.

\section{Evaluating Representations}

In some cases, students' past experiences may allow them to focus quickly on a set of attributes in a problem situation or representation when accomplishing a goal. In cases where students have no, or limited, past experience with a situation or representation, they must monitor their solution process more carefully. In such cases, criteria - knowledge structures for evaluating representations - can become critical resources that help students regulate their problem-solving activity. Judgments about representations are often made in relation to accomplishing a particular goal. A criterion for arrays as representations of rectangular area is that they be drawn to scale. Satisfying the to-scale criterion is critical when drawing replicas of problem situations, but the correct row and column structure will suffice when determining areas as total numbers of array elements.

As discussed in the beginning of the article, diSessa (2002; diSessa et al., 1991) characterized students' ability to generate, evaluate, and refine representations as metarepresentational competence. In further work, Izsák (2003, 2004a) analyzed cases in which eighth-grade students learned to represent and solve problems about linear motions, in part, by coordinating several criteria for algebraic representations and refining the contexts in which they applied certain of those criteria. This research has demonstrated not only that students posses criteria for representations, but also that such criteria can play an important, if implicit, role in students' understandings about the role of external representations in problem solving.

\section{DATA AND METHODS}

Data for this article came from a collaboration between the CMW project and Mrs. Stuart ${ }^{5}$ during the 2000-2001 school year. Mrs. Stuart had taught for approximately

\footnotetext{
${ }^{5}$ All names are pseudonyms.
} 
20 years and was teaching fifth grade in a small urban district in the Midwest. During the collaboration, she taught the district-adopted Everyday Mathematics (The University of Chicago School Mathematics Project, 1995) curriculum in the mornings and piloted the CMW multidigit multiplication unit 3 afternoons a week. Mrs. Stuart's students had already studied the lattice (or Galosia) method for multidigit multiplication. Figure 3 demonstrates that the method represents factors vertically and horizontally and places value for partial products along diagonals. Mrs. Stuart wanted to pilot the CMW materials because, in her judgment, her students did not understand why the lattice method works. Her students had also worked with arrays of dots in fourth grade but had not studied connections between rectangular area and multidigit multiplication methods. Mrs. Stuart began the CMW lessons at the end of November and concluded them in mid January. Her Everyday Mathematics lessons during the same weeks focused on fractions, decimals, and percents.

I videotaped all 10 of Mrs. Stuart's CMW multiplication lessons to record how she implemented the materials, and I interviewed four pairs of her students to investigate their understandings of tasks contained in those lessons. The lesson videos allowed me to connect students' problem-solving performance during the interviews to classroom instruction. For instance, when students discussed areas as "insides" of rectangles and the issue of scale, I knew that they had discussed similar ideas in class.

I asked Mrs. Stuart to identify students that ranged from high to low achieving, but not students that were receiving special services. In addition to a range of achievement levels, I asked for students who worked well together, who were willing to explain their thinking, and who attended school regularly. In the end, I interviewed a pair of high-achieving girls, a pair of high-achieving boys, a mid-achieving boy and girl, and a mid- and a low-achieving girl.

Figure 4 summarizes the chronological order of Mrs. Stuart's CMW multiplication lessons and the student interviews used in the analysis presented here. (A few additional lessons and final interviews occurred after the holidays.) I interviewed

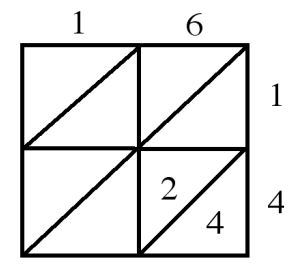

(a)

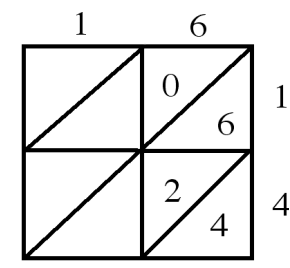

(b)

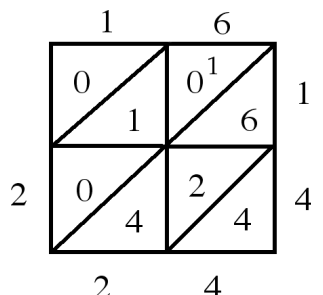

(c)

FIGURE 3 The lattice method for $14 \times 16=224$. (a) $6 \times 4$ is recorded as two $10 \mathrm{~s}$ and four $1 \mathrm{~s}$. (b) $6 \times 10$ is recorded as zero $100 \mathrm{~s}$ and six 10s. (c) The complete computation showing addition of partial products along diagonals. 


\begin{tabular}{|c|c|c|c|}
\hline $\begin{array}{c}\text { Jill \& } \\
\text { Ellie }\end{array}$ & $\begin{array}{c}\text { Maisha \& } \\
\text { Lauren }\end{array}$ & $\begin{array}{c}\text { Bill \& } \\
\text { Nick }\end{array}$ & Rick \& Elaine \\
\hline \multicolumn{4}{|c|}{ Lesson 1 } \\
\hline \multicolumn{4}{|c|}{$(11-28-00)$} \\
\hline $12-1-00$ & $11-30-00$ \\
\hline \multicolumn{4}{|c|}{ Lessons 2, 3, and 4} \\
$(12-4-00,12-5-00,12-6-00)$ \\
\hline $12-8-00$ & $12-7-00$ & $12-13-00$ & $12-13-00$ \\
\hline $12-15-00$ & $12-14-00$ & \\
\hline \multicolumn{3}{|c|}{ Lessons 5, 6, 7, and 8 } \\
\hline \multicolumn{3}{|c|}{$(12-15-00,12-18-00,12-19-00,12-20-00)$} \\
\hline $12-22-00$ &
\end{tabular}

FIGURE 4 Dates for Mrs. Stuart's Children's Math Worlds multiplication lessons and for student interviews. (Mrs. Stuart's December 15, 2000, lesson occurred after Jill and Ellie's interview on the same day.)

two of the pairs once a week over the course of Mrs. Stuart's CMW instruction (Jill and Ellie, Maisha and Lauren), but, due to scheduling constraints, interviewed the remaining two pairs only once in the middle and once at the end of the unit. The analysis following focuses on Jill and Ellie, because they provided the most detailed data on how students can coordinate understandings of multiplication, arrays, and rectangular areas. I use data on the remaining three pairs of students to demonstrate that other students in Mrs. Stuart's class evidenced similar understandings and faced similar challenges.

The 45- to 50-min semistructured interviews (Bernard, 1994, chap. 10) took place in the principal's office. During the interviews, I had students solve problems like those that they were working on in class. I asked the students to work together and to ask each other questions. When students were either done with a problem or stuck, I led a discussion to probe what they were thinking and what difficulties, if any, they were having. During these discussions, I mainly asked students to elaborate their explanations, but, at times, I introduced alternatives to their ideas. If students rejected my ideas and stuck to their own, I had further evidence of students' conviction. If students accepted my ideas, I looked to see if they could elaborate in ways reflecting understanding. I also varied problem situations to examine whether, and how, students applied similar ideas across contexts. Consistent with semistructured interview techniques, I posed subsequent problem situations in response to ideas that students expressed. I afforded students opportunities to coordinate understandings of multiplication, arrays, and rectangular areas through the sequence of tasks, by encouraging students to pursue their ideas and by having students reexamine their work.

Initial interview tasks provided access to some of the students' already-established connections between multiplication and situations containing equal groups. 
The first three tasks were word problems accompanied by directions to "draw a diagram and write an equation that would solve the problem."

1. Maria has borrowed five books from the library. If she borrows two more, how many library books will she have all together?

2. How many tomato plants are in Jim's garden if there are six plants in each of three rows?

3. A supermarket chain has seven stores in each of four cities. How many supermarkets does the chain have in all?

Problem 1 can be solved by adding or counting, but not by using multiplication. Problem 2 explicitly describes an array and can be solved using multiplication, addition, or counting. Problem 3 describes equal groups, but not an array, and can also be solved using multiplication, addition, or counting. For subsequent interview tasks, students used arrays of dots printed on paper, creating permanent records while working with materials essentially the same as the whiteboards used in class. Sometimes, I presented rectangles drawn on dot paper and asked students to find the perimeter and area. Other times, I asked students to draw rectangles that showed particular multiplication problems.

I recorded the interviews using two video cameras, one to capture the students and one to capture what they wrote. I also kept all of the students' written work in case the videotapes did not capture important aspects clearly. I transcribed the interviews in their entirety and added notes indicating what students wrote and what hand gestures they used. I analyzed the resulting transcripts and written work using microgenetic methods (Schoenfeld et al., 1993). First, I went through individual segments of transcript line by line, examining students' utterances, hand gestures, and other actions for evidence of what they were thinking as they worked on the tasks. More often than not, data in a single segment were open to multiple interpretations. I then tried to knit local accounts into consistent, global ones, building a case for particular interpretations of the individual segments. A second researcher viewed the interview videotapes independently, found a good overall fit between the data and analysis for the main case study (Jill and Ellie), and identified a few places where the analysis needed clarification. The analysis following reflects those clarifications.

Only one student experienced difficulties when solving the three initial word problems previously mentioned. The others connected multiplication with equal groups in Problem 2 and sometimes in Problem 3. I had planned to follow Problem 3 with a problem or two that would evidence students' connections between single-digit multiplication and arrays of unit squares drawn over dots. With this data in hand, I would then pursue students' ability to construct two-digit multiplication methods using area representations. Instead of focusing on unit segments and unit squares, however, students often focused on the underlying dots. Moreover, some 
student difficulties appeared rooted in subtle differences between using arrays of dots and arrays of unit squares for representing and solving multiplication problems. In response, I investigated the range of understandings, including those of the dot perspective, on which students could build understandings of the space perspective.

\section{JILL AND ELLIE}

Jill and Ellie began the interviews able to mentally produce products of single-digit numbers quickly and accurately. They could multiply two-digit numbers using the lattice method, but they did not understand fully the representation of place value and, in particular, why one adds diagonally. Moreover, Jill and Ellie's diagrams for the three initial word problems previously mentioned (see Figure 5) demonstrated that the girls could connect multiplication to some situations that contain equal groups of discrete objects. Ellie explained that the dual numbers in her written work for Problem 2 reflected three rows with six in each. As Ellie was talking, Jill gave a similar explanation while pointing at her own work: "One row of six, two rows of six, and three rows of six." When I asked the students if they could solve the problem

Jill Ellie

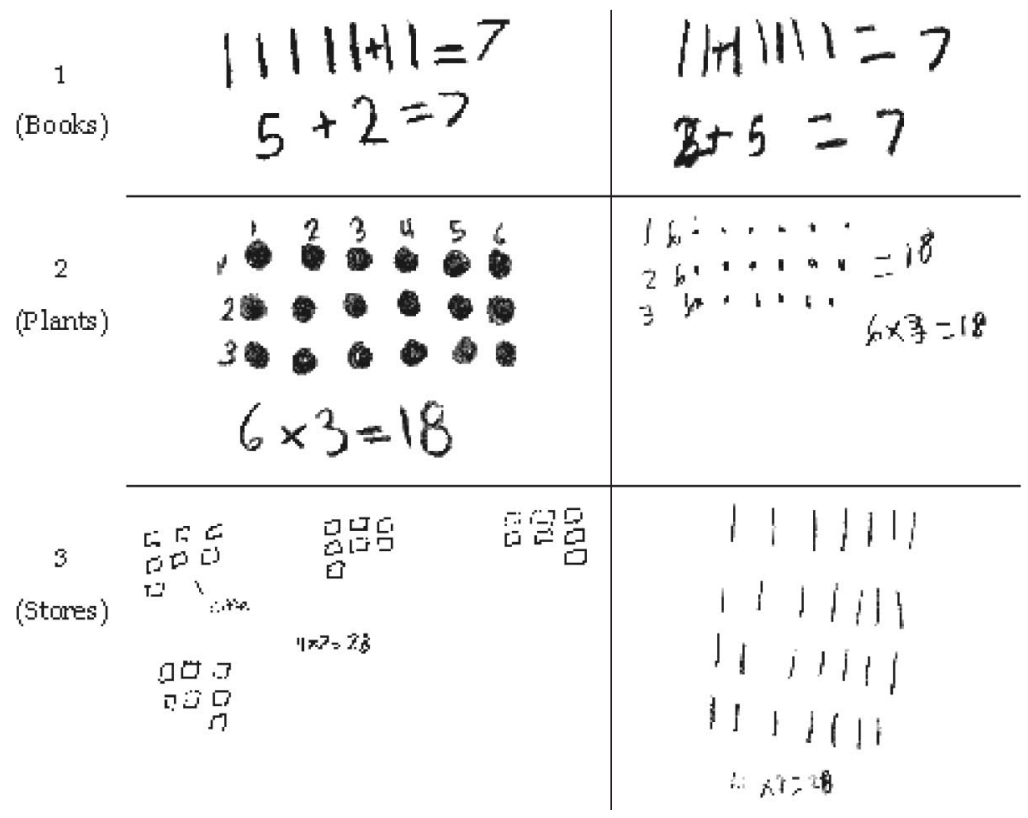

FIGURE 5 Jill and Ellie's diagrams for the three word problems. 
without using multiplication, they calculated $6+6+6$ and, in a separate solution, calculated $3+3+3+3+3+3$. Jill and Ellie's solution to Problem 3 provided further evidence that they understood relations among multiplication, addition, and equal groups because they identified four groups of seven across two different diagrams - one that showed equal groups as rows in an array and one that did not. Ellie concluded that "they both show the same thing." As mentioned previously, Mrs. Stuarts' students had prior experiences with arrays of dots in the fourth grade.

I organize the analysis of Jill and Ellie's learning trajectory into two phases. During Phase I, Coordinating Dot and Space Perspectives on Arrays, the students' main accomplishments included (a) differentiating the dot and space perspectives; (b) coordinating dimensions and totals within each perspective; and (c) understanding that, in the dot perspective, one uses a single representational feature - dots - to determine both dimensions and totals, whereas in the space perspective, one uses unit segments to determine dimensions and unit squares to determine totals. During Phase II, Refining a "to-Scale" Criterion for Representations of Rectangular Areas, Jill came to understand that, in the space perspective, arrays do not have to be drawn to scale to determine areas of represented rectangles: It suffices for arrays of unit rectangles to have the correct number of rows and columns. Data from the two phases evidenced particularly Jill's refinement and reorganization of knowledge for selecting attributes, using arrays, and evaluating arrays as representations sufficient for determining rectangular areas.

In presenting data, I label lines of transcript with both letters and numbers (e.g., A1, A2, B1, B2). Alphabetical order corresponds to chronological order of excerpts, and consecutive numbers correspond to contiguous lines of transcript within excerpts. I used the following conventions when preparing the transcripts:

// ... // denotes concurrent talk.

[... denotes a comment I think a student made.

(inaudible) denotes a time when I could not understand what a student said.

(... ) denotes a comment that I inserted while preparing transcripts.

"..." denotes something that a student wrote down.

\section{Phase I: Coordinating Dot and Space Perspectives on Arrays}

Phase I occurred during the first interview with Jill and Ellie. This interview took place 3 days after the only CMW multiplication lesson that Mrs. Stuart had taught so far (see Figure 4). Mrs. Stuart understood that her students had studied area and perimeter in fourth grade and had begun her lesson with a quick review. Instead of asking for definitions, she had asked for examples where one would need to find perimeter or area. Students had offered a fence around a house as an example for perimeter and finding the "inside of a building" as an example for area. Mrs. Stuart 
had then introduced the CMW whiteboards focusing on both dots and spaces. When discussing dimensions of rectangles, she had explained that three dots make two unit segments and had supported her explanation with a diagram drawn on the overhead. When discussing areas, Mrs. Stuart had drawn unit squares inside of rectangles but had not explicitly discussed the array structure or covering property of those squares. Mrs. Stuart had then asked her students to draw diagrams that matched "number models." Jill and Ellie had produced diagrams with the correct number of rows and columns in the space perspective during the lesson, but, at the beginning of Phase I, combined elements of the dot and space perspectives to determine incorrect dimensions and totals.

Data. Phase I began with the fourth interview task, which presented three rectangles and asked the students to find the perimeter and area of each. Figure 6a shows the rectangles, and Figure 6b shows Ellie's initial incorrect dimensions for the first. Jill labeled her rectangle the same way. After the students agreed that the dimensions were three and four, Ellie stated that "the area is the inside" and then a few exchanges later continued, "Eight plus six is 14 for the perimeter, and then the area would be 12 , right? 'Cause you multiply three by four, right?" A moment later, however, she questioned the vertical dimension:

A1: Ellie: Wait. Are these only two or three? Are we doing dots or units?

A2: I: You tell me.

A3: Jill: Units then.

A4: I: Does it make a difference?

A5: Ellie: Well, yeah, because look this can be, this is either two units (pointed to the left-hand edge of the rectangle), 'cause the spaces between
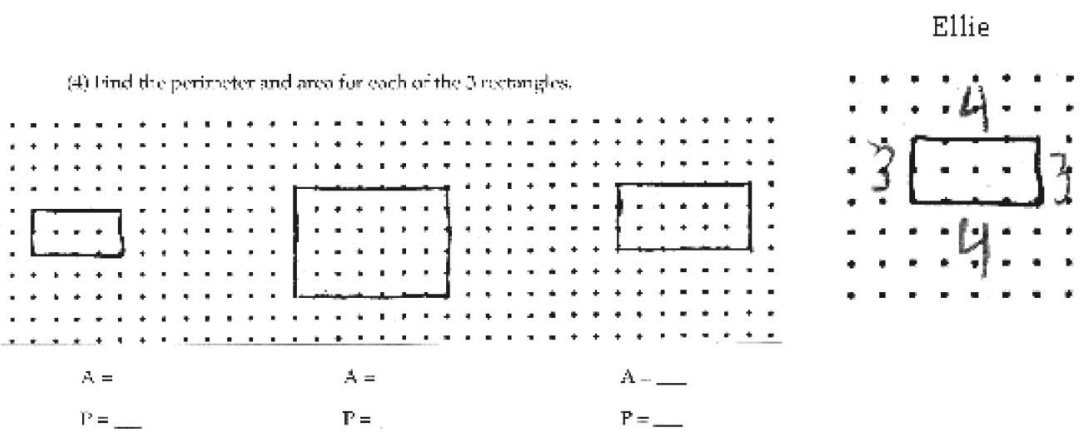

(a)

(b)

FIGURE 6 (a) Problem 4 (Find the perimeter and area for each of the 3 rectangles). (b) Ellie's initial labels for the first rectangle. 
them, there are two spaces, or it can be three 'cause you've got three dots. Do you want to do dots, 'cause that's how we usually do it in class?

A6: Jill: Yeah. But then that would be five dots (pointed toward the rectangle).

Jill and Ellie changed their fours to fives and stated that the "area" and "perimeter" would be 15 and 16, respectively. Subsequently, they explained that they had studied arrays together in fourth grade and there they had always counted dots. Ellie expressed a preference for working with dots, and Jill agreed, saying, "Cause it is more like arrays, the dots."

Analysis. Jill and Ellie's initial understandings for selecting attributes were based, at least in part, on their past experiences with arrays of dots. Moreover, Ellie's question about using dots versus units (line A1) suggested that her inconsistent numeric labels may have been the result of undifferentiated dot and space perspectives. Jill's focus on units (line A3), combined with her comment about dots being like arrays, suggested that she may not have differentiated the two perspectives either. Although the students did not restrict their use of the terms area and perimeter to the space perspective, they did understand that dots and spaces gave different dimensions (lines A5 and A6).

Data. To gain further access to Jill and Ellie's understandings of dot and space perspectives, I asked the students to work rectangles "both ways." Using the dot perspective on the second rectangle, Jill and Ellie correctly counted six dots down and eight across. The students multiplied $6 \times 8$, and Ellie concluded, "So area is 48 and the perimeter is, 16 , and 16 plus 12, isn't that 28?" Jill agreed. I then asked Jill and Ellie to reexamine the first two rectangles using the space perspective. For the first rectangle, the students found the correct dimensions of two and four and wrote " 8 " for area and " 12 " for perimeter. For the second rectangle, the students found and wrote the correct vertical dimension of five before Ellie predicted the horizontal dimension:

B1: Ellie: Jill, that's going to be seven because it seems like this (pointed to her previous solutions using the dot method) has always been one less than the other one, so that should be seven (Jill wrote " 7 " along the top and bottom of the rectangle).

B2: Jill: Yeah. It is.

B3: Ellie: So that's neat.

B4: Jill: //That's neat.

B5: Ellie: That's neat, 'cause// when you do the units, how it is just one less. 
Ellie stated that $5 \times 7=35$ would give the area and calculated out loud "seven plus seven is 14 , plus 10 is 24 " for the perimeter. She described the first method as counting "all the dots from top to bottom or right to left" and the second method as counting "the spaces between the dots." To illustrate one space, Jill drew a horizontal line segment from one dot to an adjacent dot. Ellie concluded, "Cause that is what we did yesterday in class." (Ellie apparently referred to the one CMW lesson that had taken place 3 days prior to this interview.)

Analysis. Jill and Ellie coordinated appropriate arithmetic operations with the goals of determining perimeters and areas: They consistently added dimensions to determine what they termed perimeters and multiplied dimensions to determine what they termed areas. Ellie also articulated explicit relations between the dot and space perspectives when she noted that space dimensions were always one less than dot dimensions (lines A1, A5, B1, and B5). This, in turn, may have helped the students realize the importance of differentiating the two perspectives. Although Ellie indicated the correct representational features for determining dimensions within the dot and space perspectives, subsequent data would evidence that the students had to still coordinate their understandings of dimensions and totals for each perspective with their understandings of "inside" and "outside."

Data. I asked Jill and Ellie to explain once more how to calculate "perimeter" in the dot perspective. Jill said, "You add up all the things on the outside," and Ellie referred to edges when stating that she "would be adding four lines, four lines of dots." I then asked the students how to calculate the "area" using the dot perspective. Ellie stated, "Multiply the two different numbers," and Jill stated, "Yeah. You multiply [the number], the top and the side." When I asked if there was another way to "figure out area," Ellie offered, "You count the dots on the inside, right? Isn't that what area is, right?," but was confused when she only counted 24 dots in the interior:

C1: Ellie: Why is that only 24 ? Oh, do you have to add the, I think you've got to add the two sides, don't you?

C2: Jill: 'Cause there's six rows with eight in each. That's like saying eight (pointed to the second row of dots) plus eight (pointed to the third row of dots) plus eight (pointed to the fourth row of dots) plus eight, //which is basically multiplying.

C3: Ellie: Oh. Yeah. You gotta to count these.//

When Ellie subsequently explained, "Eight rows and each one contains six dots," she apparently focused on columns.

Analysis. Ellie refined her understandings for selecting attributes within the dot perspective. She evidenced connections between "perimeter" and "outside," 
and her comments suggested that she focused on edges of rectangles when using the word outside. Her description of adding "four lines of dots" was consistent with her perimeter computations for the $3 \times 5$ and $6 \times 8$ arrays in the previous section, but it left unclear whether she realized this method counted corner dots twice - once as part of the horizontal and once as part of the vertical dimension. ${ }^{6}$ Ellie's count of 24 dots indicated that she initially focused on strict interiors when using the word inside, but then used her numeric understandings of multiplication (she had multiplied $6 \times 8=48$ ) to question her work (line C1). Recall that Ellie had also multiplied to solve correctly the second problem shown in Figure 5. Now, she had to coordinate her existing multiplicative relation between dimensions and totals in the dot perspective with her understandings of "inside" and "outside." After listening to Jill connect equal groups of eight dots to multiplication (line C2), Ellie focused on all 48 dots organized into equal groups of six dots when determining the "area." Ellie may have refined her notion of "inside" in the dot perspective to include dots along edges, but the data did not provide direct evidence.

Data. At this point, I returned Jill and Ellie's attention to the space perspective. Ellie stated that they should have five rows of seven, and the students began to count horizontal line segments. Figure 7a shows that the students traced line segments as they counted successive rows, starting with the top edge. The students were troubled when they arrived at 35 at the end of the fifth row. Jill observed, "We are already at 35, and we haven't done anything else." Ellie concurred, "Wait. Wait. This isn't good." The students agreed that they were getting too many segments, but disagreed over which ones they should count. Ellie thought that they should count just the horizontal segments, including those in the sixth row along the bottom edge, whereas Jill thought that they should count vertical ones as well. Figure $7 \mathrm{~b}$ shows further vertical line segments that Jill traced as she explained her thinking. Jill and Ellie tried to resolve their confusion in the following exchange:

D1: Jill: Maybe the unit thing just doesn't make sense [in that] (pointed toward her work shown in Figure 7b).

D2: Ellie: Well I don't know, but how does that work? How does that work? Like how would you figure out the area for that? 'Cause the area is not 35 , but when you multiply five times seven you get 35 .

D3: Jill: Then the area, you must not be able to multiply five times seven, because if you multiply five times seven you're not multiplying the array. It is not really an array. //It's only ...

\footnotetext{
${ }^{6}$ Although Ellie's initial labels for the first rectangle in Figure 6b may have reflected counting dots if she did not consistently count corner dots twice, I do not think that she or Jill counted dots in this way because they changed their fours to fives when focusing on dots (line A6).
} 


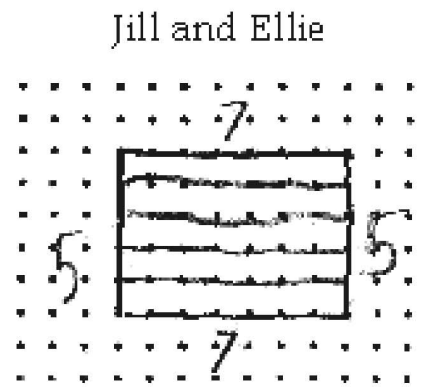

(a)

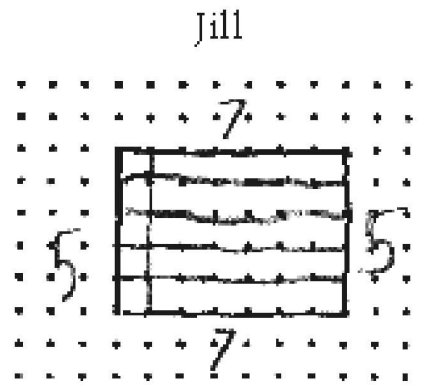

(b)

FIGURE 7 (a) Jill and Ellie counted horizontal line segments. (b) Jill counted vertical line segments as well.

D4: Ellie: Oh.// So maybe you are not multiplying an array. Maybe you're just (inaudible). Oh! That would be cool. That's cool. So I don't think you could count on the inside, 'cause you don't come up with the right answer.

Analysis. When shifting to the space perspective, Jill and Ellie struggled to coordinate dimensions and totals. The students understood that the dimensions of the second rectangle would change from six and eight to five and seven, and they used their numeric understandings of multiplication to predict that the area of the rectangle would be 35 . The data strongly suggested, however, that Jill and Ellie's notion of "inside" did not include covering, and so the students relied on other understandings as resources for selecting attributes. Within the dot perspective, Jill and Ellie had used a single representational feature - dots - to determine both "areas" and "perimeters." The students inappropriately extended the use of a single representational feature - this time, unit segments - to determine both dimensions and totals in the space perspective. Although Jill and Ellie used their knowledge of multiplication to detect that they were counting too many segments (lines D2 and D3), they had yet to find a representational feature that would give their expected total of 35. When Jill explained that they were not working with an array (line D3), she may have meant that their representation was not an array of dots. Jill and Ellie's comments (lines D3 and D4) strongly suggested that the students had reached an impasse in understanding the space perspective.

Data. Because Jill and Ellie appeared stuck, I asked if they could "think of a different thing to count." The students thought for a moment, and Jill offered, "The squares inside the shape." I asked Jill to show what she meant, and each student 
shaded one unit square. To try their new idea, the students counted unit squares one by one and arrived at 35 . As they finished counting, the following exchange ensued:

E1: Ellie: Hey! That works! The squares figure out ... the squares work! That's cool. So you have to figure out ... count the squares in it.

E2: Jill: But that still wouldn't be the correct area 'cause if eight times six has 48 , that still only has ...

E3: Ellie: But look, but look! Five times seven is 35, and we got 35 boxes.

E4: Jill: When we counted boxes. Yeah.

E5: Ellie: Wait. But see, if the area is that, then the area must be in boxes when you're doing the little, the units.

E6: Jill: So the area could be different

E7: Ellie: Right. That's cool.

E8: Jill: in a shape. I never knew that.

A few exchanges later, Jill elaborated her last comment by saying that "the area in shapes can change whether you're using boxes or dots."

After Jill and Ellie used the space perspective correctly on the third rectangle in Problem 4 (see Figure 6), I asked if they could "think of the boxes as being in an array." Ellie responded, "The boxes could be a dot, if you were to separate out all the boxes." She proceeded to add dots to the center of each unit square (see Figure 8). Ellie apparently followed Jill's explanation, but she expressed uncertainty about her own understanding of the space perspective: "You couldn't use the unit, the, just the space, you'd have to use the box. I don't know why that's like that."

Analysis. Jill and Ellie confirmed that unit squares "work" by counting rather than by noticing unit squares cover, providing further evidence that they did not at-

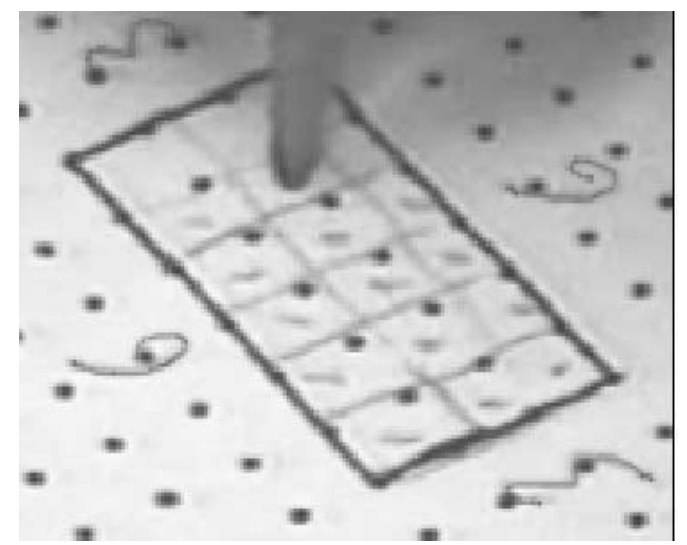

FIGURE 8 Jill added dots to explain unit squares as an array. 
tend to covering when selecting attributes. Jill did not explain why she focused on "squares inside the shape," but perhaps she remembered that Mrs. Stuart had discussed squares during her first CMW lesson. That the students counted all 35 squares one by one, however, suggested that they were uncertain of the answer and so fell back on a strategy in which they had high confidence. Moreover, Ellie appeared surprised and excited when announcing that "the squares work" (line E1), whereas Jill doubted her method because she focused on $6 \times 8$ (line E2). Jill's focus on this product may have originated in her earlier comment that, when multiplying $5 \times 7$, "you're not multiplying the array" (line D3). In particular, Jill's strong connection between arrays and dots may have returned her attention to the dimensions of six and eight even as she counted unit squares.

Jill's subsequent mention of two different answers for area (line E6), followed by her comment that "the area in shapes can change whether you're using boxes or dots," suggested that she further differentiated the dot and space perspectives. Moreover, Jill was apparently realizing that shifting from dots to spaces affected dimensions and totals together. Such differentiation of the dot and space perspectives, and the coordination of dimensions and totals within each, had the potential to support Jill's future problem solving because increasingly explicit understandings of the consequences of using dots or spaces could help her focus more carefully on particular representational features. Finally, Jill elaborated the notion of unit squares in an array - a notion that I introduced - with her comment that "the boxes could be a dot, if you were to separate out all the boxes." Jill's description of separating boxes suggested that she was coordinating understandings of totals in the dot and space perspectives and possibly attending to covering, at least implicitly.

Although Ellie began connecting unit segments with dimensions and unit squares with totals in the space perspective (lines E3 and E5), her final admission that she "[did not] know why that's like that" made clear that her coordination was partial. Ellie apparently understood that the product of dimensions measured in unit segments agreed with the total number of unit squares, but she did not seem to connect unit segments along the perimeter with equal groups of unit squares, even though her work on Problems 2 and 3 suggested strong connections between multiplication and equal groups in other contexts (see Figure 5). Thus, her access to connections between multiplication and the array structure changed across problem contexts.

Summary. Jill and Ellie must not have fully understood the correct diagrams that they produced during Mrs. Stuart's first CMW lesson. The interview data indicated that the students did not yet differentiate the dot and space perspectives at the beginning of Phase I or fully coordinate representational features with dimensions and totals within each perspective. Jill's work during Phase I-and, to a lesser extent, Ellie's - evidenced learning through refinement and coordination of knowledge for selecting attributes. One example occurred when Jill and Ellie coordinated dimensions and totals within and between the dot and space perspectives. A 
second occurred when the students discovered that, in the dot perspective, edges must be considered as inside to preserve the multiplicative relation between dimensions and totals. A third occurred when Jill and Ellie reexamined their expectation that a single representational feature could be used for both dimensions and totals in the space perspective. Although the students' past experiences with arrays of dots constrained emerging understandings of the space perspective sometimes, Jill's final work (see Figure 8) suggested that she used arrays of dots to solidify her understanding of rectangular areas as arrays of unit squares. These data evidenced the gradual transformation of novice into more expert knowledge of area because conceiving arrays of unit squares could potentially support fuller understandings of areas as coverings and the transformation of length into area measurements (as suggested by Simon \& Blume, 1994).

\section{Phase II: Refining a "to-Scale" Criterion for Representations of Rectangular Areas}

Phase II began during the second interview with Jill and Ellie and continued into the fourth. Mrs. Stuart taught her second, third, and fourth CMW multiplication lessons in between the first and second interviews (see Figure 4). The CMW project developed the second lesson in response to difficulties that Jill, Ellie, and other interview students were having focusing on the space instead of the dot perspective. (I discuss data on the remaining students later in the article.) During the lesson, Mrs. Stuart had students draw rectangles on blank parts of their whiteboards by marking off vertical and horizontal unit segments and forming corresponding unit squares. She then had students number unit segments and unit squares to emphasize the representational features used for perimeter and area. Mrs. Stuart's third lesson provided further opportunities for students to reinforce understandings of the space perspective, and Jill and Ellie did not evidence further difficulties determining dimensions and totals in the space perspective during subsequent interviews.

Mrs. Stuart's fourth CMW lesson introduced the notion of sketching rectangles to scale and provided the backdrop for Phase II interviews with Jill and Ellie. The CMW project and Mrs. Stuart's shared intention for the lesson was for students to understand sketches as less detailed representations suitable for work with larger numbers. A sample phrase that Mrs. Stuart used to communicate the goal of sketching to her students was "to make [the rectangles] a little bit smaller than they would be if you were using the dots." A key issue for the research was whether students would continue to interpret to-scale rectangles in terms of rows and columns of unit squares even when arrays were not rendered explicitly.

My original intent for the second interview was to assess what Jill and Ellie understood about Mrs. Stuart's instruction regarding scale drawings. As I listened to the students' initial explanations, however, I could not tell if they were simply repeating what had been said in class. To better understand connections the students 
made among multiplication, arrays of unit squares, and scale drawings, I began varying contexts for the use of rectangular representations. Jill and Ellie's initial responses contained seemingly contradictory comments, some of which possibly evidenced capabilities untapped by the CMW materials or Mrs. Stuarts' implementation of those materials. Although Mrs. Stuart's instruction emphasized scale drawings, Jill in particular seemed to have a tacit understanding that drawings did not have to be exact replicas to solve area problems. As I posed further questions and tasks to better understand what Jill was saying, I apparently supported her increasingly explicit understanding that to-scale drawings are not required to determine areas of represented rectangles so long as the row and column structure of not-to-scale unit rectangles matches the row and column structure of unit squares.

Jill's insight, which emerged over the course of three interviews, illustrates the arrows in Figure 1 because understanding that counting not-to-scale unit rectangles suffices (knowledge for using representations) allowed her to reduce emphasis on the to-scale criterion (knowledge for evaluating representations), and, as a result, she apparently separated the underlying row and column structure from the shape of individual elements (refining her knowledge for selecting attributes). The knowledge in pieces perspective, with its attention to knowledge elements of diverse types, handles such data well. Data on the remaining students provides further examples of students understandings of to-scale rectangles as representations. In the concluding discussion, I argue that Jill's accomplishment was particularly significant when considered as part of a longer possible learning trajectory in which students construct relations between representations and situations across topics and domains that afford solutions to problems.

Data. When I first asked Jill and Ellie to draw rectangles on blank paper to show multiplication problems, they marked off segments across and down that were about the same length, similar to Mrs. Stuart's demonstration. Jill commented that she needed tick marks along the perimeter so that she would not "get confused at what's a unit," and Ellie commented that they wanted to make spaces "at least somewhat even." I then had the students draw fresh rectangles without any marks or labels and asked whether those could show different multiplication problems. Jill drew a rectangle such that the height was approximately half the width and explained that her rectangle could be $50 \times 100,2 \times 4,4 \times 8$, or $6 \times 12$ "as long as the thing is half of it." To test the strength of connections that the students evidenced between lengths and widths of drawn rectangles and ratios of numbers being multiplied, I asked whether Jill's rectangle could be $10 \times 100$. Jill said no because 10 is a tenth of 100 , and the height of her rectangle was half the length. The students made several additional comments consistent with the understanding that lengths and widths should be in the same ratio as the numbers being multiplied.

I wondered, however, whether Jill and Ellie's comments were constrained by their perceptions of appropriate answers in school settings and so asked them to 
imagine drawing rectangles for themselves, not for class or homework. Jill drew the rectangle shown in Figure 9a and said, "You could just say it's four and 10 if you really wanted to. And it wouldn't much matter 'cause you could still multiply those (pointed to her "4" and "10" labels) and you could find out just the area of the shape.” When I asked if Ellie's rectangle shown in Figure 9b could also be $4 \times 10$, Jill stated:

F1: Jill: It could be 4 by 10, if, if, well it couldn't be 4 by 10 , but if you were just drawing it for any old reason you really wanted to, and somehow math just came in handy for something other than homework and school, then you could make it like that, but it wouldn't be to scale, but you would still be able to multiply things, but you wouldn't find the correct area.

Both students subsequently agreed that you would have to draw rectangles to scale to find areas.

When I asked whether vertical and horizontal units would be the same in a not-to-scale rectangle, the students answered, "No." When I asked whether this difference mattered, Jill responded, "Depends if you're multiplying just for fun, or if you really want to find the area." Both students appeared to understand the distinction that Jill articulated, but, during the balance of the second interview, Ellie's comments evidenced a stronger requirement that lengths and widths of rectangles match the relative sizes of numbers, even when multiplying "just for fun."

Analysis. Jill and Ellie's responses at the beginning of Phase II raised questions about connections they evidenced among multiplication, area, and rectangles drawn to scale. When I asked the students to draw rectangles to show multiplication, they drew rectangles approximately to scale as if I had asked specifically about area. Did these responses reflect such tight connections that the students always thought about area when thinking about multiplication and rectangles, or

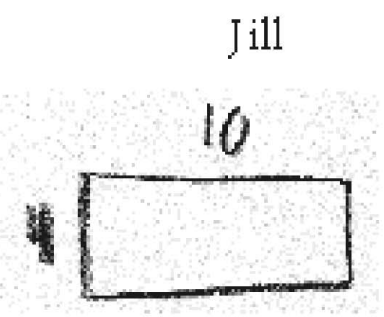

(a)

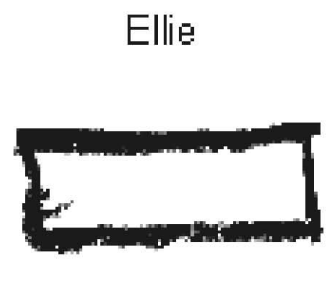

(b)

FIGURE 9 (a) Jill's not-to-scale $4 \times 10$ rectangle. (b) Ellie's rectangle. 
were the students producing what they thought to be appropriate answers in school settings? Explicitly inviting the students to think about out-of-school contexts provided some evidence that Jill in particular might consider different relations among multiplication, area, and rectangles depending on the problem-solving context. Initially, she seemed to say that you could use not-to-scale drawings to determine the area of a rectangle, but moments later she rejected this idea (line F1).

Just what Jill meant by the alternate "for fun" setting remained unclear. One meaning she may have had was that using a not-to-scale array of unit rectangles would suffice to determine the answer to a multiplication problem. Such sensitivity to relations between representations and problem-solving goals would evidence metarepresentational competence. A second meaning she may have had was that a rectangle could serve simply as a graphic organizer for recording factors and products. This meaning would undermine claims that Jill evidenced metarepresentational competence if she did not attend to the underlying row and column structure. Thus, I tried to better understand just what Jill meant by "for fun" during the next interview.

Data. At the beginning of the third interview, which occurred 1 week after the second, Jill and Ellie recalled the two discussed purposes for drawing rectangles and the issue of scale. I asked them to "draw a rectangle that would show you how to multiply seven times nine." Both drew approximately to-scale rectangles that showed seven rows of nine unit squares. When I asked how accurate the rectangles needed to be, the students gave different answers. Ellie said, "Fairly accurate," and elaborated her perspective by explaining that "boxes" should be about the same size "'cause you're working with the same things." She demonstrated different-sized boxes with the drawings shown in Figure 10a.

In contrast, Jill said, "As long as it has 63 boxes, you're OK." She said that one could work with Ellie's "two weird sized boxes" and went on to draw 63 boxes as shown in Figure 10b. When she was done, Jill stated, "That, strangely enough, is 63 boxes. And you could just say this is seven (wrote " 7 " across the top) and this is nine (wrote "9" on the left-hand side)." When I asked, Jill indicated that her drawing showed neither seven boxes across nor nine boxes down. She then crossed out and moved boxes so that her drawing did have seven boxes across and nine down as shown in Figure 10c. Jill made clear that she combined the shaded boxes with adjacent boxes and so did not leave uncovered space in the middle of her work. At this point, I asked Jill to recall questions that Mrs. Stuart had asked during previous classes. Jill discussed nine rows of seven, made connections to the computation $7 \times$ 9 , and demonstrated how she would begin to rearrange and resize her 63 boxes into rows of seven equal-sized boxes.

Analysis. Although the first rectangles that Jill and Ellie drew to show $7 \times 9$ suggested a tendency to draw rectangles to scale even when multiplying just for 
Ellie

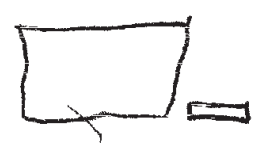

(a)
Jill

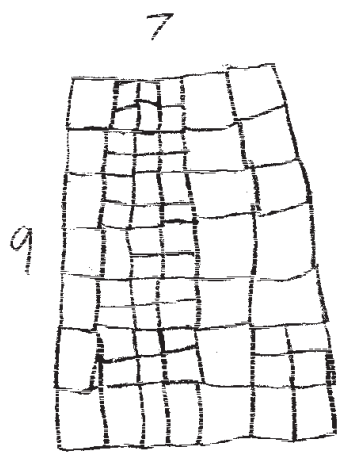

Jill

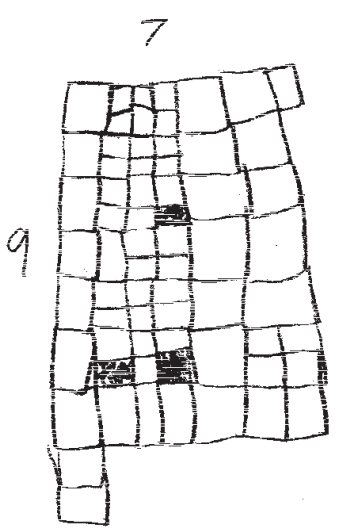

(b)

FIGURE 10 (a) Ellie's different-sized boxes. (b) Jill draws 63 boxes. (c) Jill moves three boxes.

fun, the two students responded differently to my question about accuracy. Ellie's comment about "working with the same things" suggested a criterion, closely related to the to-scale criterion, that similar features of a problem situation should be inscribed by similar features in a representation of that situation. Jill appeared intent on generating a counterexample to Ellie's idea as she rendered 63 boxes (see Figure 10b). Her initial drawing showed the correct product but not the factors, and her modified work (see Figure 10c) showed the factors and product but neither the underlying equal group structure central to whole-number multiplication nor the approximate shape of a rectangle. Jill's discussion of $7 \times 9$ and further modification of her work strongly suggested that she understood, but did not focus on, the equal group structure when drawing 63 boxes as shown in Figures 10b and 10c. Thus, Jill may have interpreted rectangles drawn for fun simply as places to record factors and products without attention to the underlying array structure. Nevertheless, I continued with the interview tasks that I had designed to access students' relations between representations and problem-solving goals.

Data. Data from the second interview left unclear whether Jill and Ellie had thought of their drawn rectangles as actual rectangles or as representations of separate, imagined rectangles for which they were trying to determine areas. Clarifying how the students understood their drawings was important because such understandings could affect whether they applied their to-scale criterion. To pursue fur- 
ther the students' connections among multiplication, to-scale rectangles, and area, I made the distinction between representing and represented rectangles more explicit by asking the students to figure out the area of the rectangular interview room with a drawn diagram.

Jill and Ellie measured the interview room with a yardstick and determined that the dimensions were $14 \mathrm{ft} . \times 16 \mathrm{ft}$. Both students drew approximately to-scale rectangles (see Figure 11) and used the lattice method to determine that $14 \times 16=224$. When I asked how accurate the rectangles had to be to determine the area of the room, Jill said, "Pretty accurate," and Ellie said, "If you want to build an exact replica of it, then you kinda need to have it exact."

To push harder on the to-scale criterion, I drew the rectangle shown in Figure $12 \mathrm{a}$ and asked whether it could be used to figure out the area of the room. Jill said,

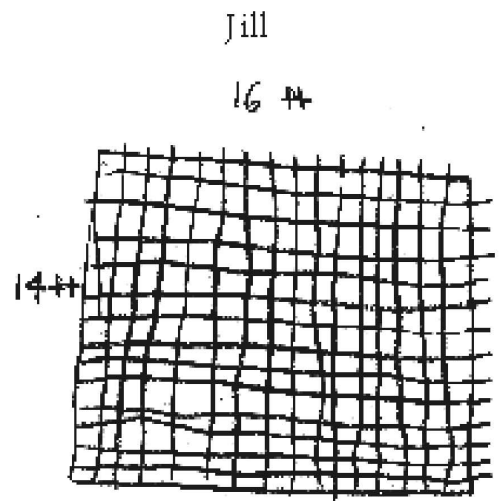

(a)
Ellie

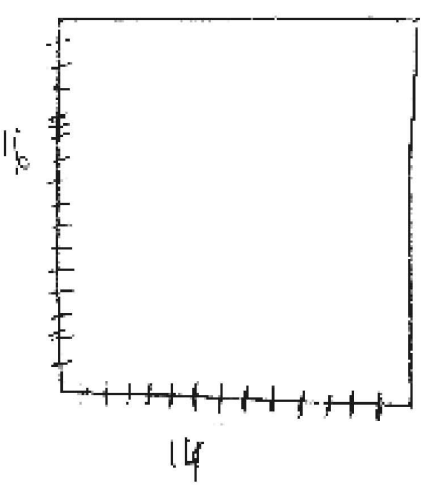

(b)

FIGURE 11 (a) Jill's first rectangle for determining the area of the interview room. (b) Ellie's first rectangle for determining the area of the interview room.
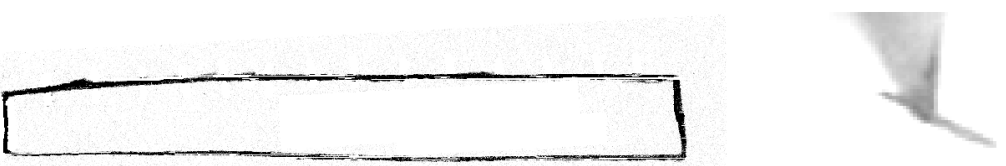

(a)

(b)

FIGURE 12 (a) My proposed rectangle for determining the area of the interview room. (b) Jill draws a unit rectangle. 
"No." Ellie explained, "You could use the numbers, but you cannot use that shape." I would have dropped scale drawings at this point, but Jill suddenly took a step toward relaxing her to-scale criterion by saying, "This would have to be a separate unit (traced the top edge of the rectangle), this would have to be a bigger unit (traced the top edge again) than that one (pointed to the left-hand side of the rectangle)." Jill went on to explain that the unit for the vertical dimension "would be like the size of a molecule." She also demonstrated the horizontal units by counting 16 segments across the top of the rectangle, pausing her pencil between each segment.

Ellie continued to object that the vertical dimension was "way too small" and the horizontal dimension "way too big" because "16 and 14 are only two apart." Even Jill seemed uncertain about using different-sized units for each dimension, saying, "It wouldn't work because then the squares would be way off; and, if you really wanted to get a measurement, you couldn't do that." When I asked if there was a way to use "my crazy rectangle anyway to figure out the area," Jill responded, "Not to this room, but it could be a hallway." She then used the vertical dimension of the rectangle to count 10 horizontal segments and concluded that the drawn rectangle was $1 \times 10$. Ellie stated, "Even if you have the different unit sizes, you just really couldn't figure it out with those squares."

Analysis. With more explicit separation of representing rectangles and the represented interview room, Jill and Ellie's initial drawings and comments were consistent with the understanding that representing rectangles had to be essentially to scale if one were to determine areas of represented rectangles. Ellie's stated goal of creating an "exact replica" and Jill's stated goal of getting a "measurement" helped explain why they drew approximately to-scale rectangles shown in Figure 11 and why they explicitly rejected the not-to-scale rectangle shown in Figure 12a.

Ellie appeared to understand and reject the possibility of using "different unit sizes" when she objected that the relative difference between vertical and horizontal dimensions of my drawn rectangle was much larger than the difference between 16 and 14. This, in turn, suggested that her to-scale criterion may have been part of a tightly connected cluster of ideas that included inscribing similar features of situations with similar features of representations (an idea that she had articulated earlier) and replicating problem situations with representations of those situations. The data did not permit closer analysis of this possibility.

I would have dropped the scale issue if Jill had not made the observation about different vertical and horizontal units. Whether Jill recalled the discussion from the previous interview about different-sized horizontal and vertical unit segments remained unclear, but her comments that "the squares would be way off" and that my rectangle could represent a hallway suggested that she would have to refine her understandings further before relaxing her to-scale criterion. I decided to pursue the issue of scale a little further because Jill's consideration of different-sized units 
suggested that she might develop new flexibility when using drawn rectangles to determine areas of separate represented rectangles.

Data. I asked Jill and Ellie how they might use their drawn rectangles to determine the total number of unit squares if they did not know the lattice method. Jill explained that she would add 14 sixteen times. I then asked the students once more if they could use my rectangle. Jill said, "No," thought for a moment, changed her answer to "Yes," and said, "The boxes would be like this (see Figure 12b), and that's not much of a box, but that's what size the boxes would be." Jill explained that she could count the boxes, but acknowledged that this would be difficult because the boxes were small and "almost shaded in." I asked Jill to imagine long, skinny rectangles that were a little bigger, so that they could be counted accurately, and asked once more if she could use my rectangle. She replied, "Yes. Now I say, 'Yes."' When I asked Jill why she had changed her mind, she replied:

G1: Jill: Because I found out that even though the boxes aren't square, they're still boxes. Like on that rectangle over there (pointed toward Ellie's work), Ellie's rectangle, they're not exactly complete boxes. Some of them are, but some of them are rectangles. And so you could just count the tiny rectangles.

I asked Jill if counting boxes for my rectangle seemed like a new idea, and she said, "Yeah. It's sorta strange." When I asked why, she explained, "Because I'm used to counting boxes, like squares." The third interview ended at this point.

Analysis. By focusing the students on ways that they used representing rectangles to determine areas of represented rectangles, I supported new coordination of particularly Jill's understandings. She focused on repeated addition when discussing adding 14 sixteen times and may have coordinated that addition with equal groups of unit rectangles, but she did not do so explicitly. Jill's comment that boxes like the one shown in Figure 12b would be hard to count raised the possibility that she objected to my rectangle because of the small size, and not the shape, of elements in the resulting array. Her comparison of boxes and squares (line G1), however, suggested that the shape of elements in an representing array was a central mathematical issue for Jill: It did not appear obvious to her that the number of elements was independent of scale and, therefore, that drawn unit rectangles were sufficient for determining the number of square feet in the interview room. Jill relaxed her to-scale criterion as she became increasingly aware that unit rectangles were sufficient for determining areas because the count remained the same. This, in turn, exemplifies the coordination indicated by the arrow between Using Representations and Evaluating Representations in Figure 1. 
Data. Mrs. Stuart's fifth through eighth CMW lessons focused on using areas of rectangles to develop numeric methods for multidigit multiplication, but I wanted to pursue further Jill and Ellie's connections between representing arrays and areas of represented rectangles. At the beginning of the fourth interview, 1 week after the third, the students recalled that they had found the interview room to be $14 \mathrm{ft}$. $\times 16 \mathrm{ft}$. and had discussed the issue of scale. Ellie explained that a rectangle is to scale if all vertical and horizontal unit segments are the "same."

Jill recalled that, even though the vertical and horizontal unit segments are different in a not-to-scale rectangle, the resulting rectangle can still be used to determine area. She then drew the rectangle shown in Figure 13a and said that it both was and was not to scale. Jill explained that her rectangle was not to scale because it did not have square units, but that it "would be the exact same area anyway." She then used the lattice method to determine correctly that her drawing contained 224 "boxes" and explained that there were 16 columns that contained 14 boxes each. When I asked for another way to count the boxes, Jill said that "there are $1416 \mathrm{~s}$ " and shaded the bottom row of unit rectangles to illustrate one group of 16. Finally, when I asked why the rectangle was to scale, Jill explained, "Because it would still be 14 by 16 " and demonstrated with hand gestures how to squeeze unit rectangles into unit squares (see Figure 13b). She elaborated further, saying that "if you were to squish [the unit rectangles] all together, they would become unit squares" and the result would give "the correct drawing and shape of a room." Ellie said, "Oh! I get what you're saying!," and commented that squeezing would make the horizontal unit segments the same size as the vertical unit segments. A few exchanges later, however, she pointed to Jill's rectangle shown in Figure 13a and stated that "this shape does not work."

Analysis. Data from the fourth interview provided further evidence that newly coordinated understandings among multiplication, representing arrays, and represented areas were emerging, particularly for Jill. First, she recalled the central idea discussed during the third interview: Not-to-scale rectangles can be used to

14

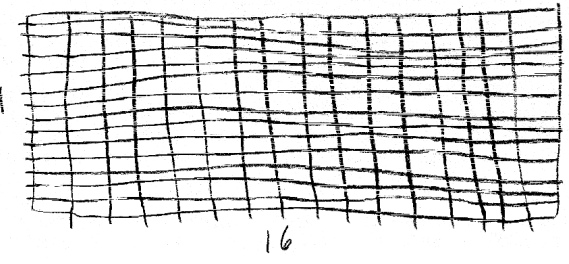

(a)

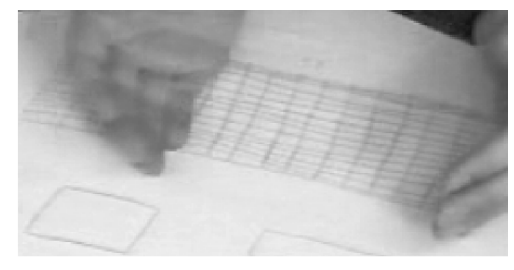

(b)

FIGURE 13 (a) Jill's not-to-scale $14 \times 16$ rectangle. (b) Jill transforms unit rectangles into unit squares. 
determine areas even though vertical and horizontal unit segments are not the same length. Second, Jill's comment that "it would be the exact same area anyway" suggested that her connection between a to-scale rectangle and the one she had drawn in Figure 13a was based on the total number of array elements. Jill's demonstrations of 16 groups of 14 and 14 groups of 16 evidenced her attention not only to the total number of unit rectangles, but also to their organization in rows and columns. Third, Jill connected to-scale and not-to-scale rectangles when she cupped her hands and explained how to transform unit rectangles into unit squares. These data contrasted with Jill's initial discussion of 63 boxes during the second interview and suggested that she now understood that the row and column structure, and not the shape, was the feature of representing arrays critical for determining areas of represented rectangles. Ellie's coordination of multiplication, representing arrays, and areas of represented rectangles appeared less flexible.

Summary. Phase I data evidenced Jill and Ellie's refinement and coordination of knowledge for selecting attributes, and Phase II data evidenced reorganized relations among particularly Jill's knowledge for selecting attributes, using representations, and evaluating representations. At the beginning of Phase II, the students' drawn rectangles and comments were consistent with the understanding that lengths and widths of drawn rectangles should be in the same ratio as the numbers being multiplied. Jill's discussion of $4 \times 10$ rectangles (see Figure 9) and her subsequent drawing of 63 boxes suggested that, when first relaxing her to-scale criterion, she lost sight of the equal group structure central to whole-number multiplication. Thus, her to-scale criterion and her understanding of equal groups in the space perspective appeared linked because she dropped both at the same time. As the students generated $14 \times 16$ arrays to represent the area of the interview room, however, Jill in particular decoupled her to-scale criterion from her understanding of the row and column structure of arrays in the space perspective. Key to this accomplishment was Jill's insight that she could use an array of not-to-scale unit rectangles in the same way as an array of to-scale unit squares. Jill's coordination of knowledge for using and evaluating representations led to refined knowledge for selecting attributes because she focused more on the row and column structure and less on the shape of elements within that structure. Jill could still draw rectangles to scale, and might even prefer to do so when determining areas, but now she demonstrated more control over relations between the representations that she generated and goals that she was trying to accomplish. Finally, Jill's discussion of not-to-scale arrays evidenced metarepresentational competence more clearly than her initial comments about multiplying "just for fun." Thus, she may have constructed a small piece of metarepresentational competence as she engaged tasks and responded to my questions during the third and fourth interviews. 


\section{THE REMAINING PAIRS OF STUDENTS}

Data on the three remaining pairs of students did not contain as extended sequences of knowledge refinement and coordination as did the data on Jill and Ellie. Nevertheless, they did contain further examples of students struggling with the dot and space perspectives and considering to-scale and not-to-scale representations for determining rectangular areas. The work of these students demonstrate that Jill and Ellie were not outliers.

Maisha and Lauren were the mid- and low-achieving students, respectively, and Figure 4 shows that the timing of Maisha and Lauren's interviews in between Mrs. Stuart's CMW lessons was the same as that for Jill and Ellie. When working on the first three word problems, Maisha appeared to understand more clearly than Lauren connections among multiplication, equal groups, and arrays. Maisha and Lauren did not evidence a connection between area and covering and so faced challenges similar to those faced by Jill and Ellie during Phase I. In particular, when working on the second rectangle in Problem 4, Maisha also tried using a single representational feature - unit segments - to determine both dimensions and totals. Whereas Jill and Ellie initially described areas as the insides of rectangles, Maisha said that, to calculate area, "You add the sides, and then you see how many units are in the center, and then you add the numbers together." She demonstrated by drawing 20 unit segments perpendicular to the perimeter of the $5 \times 7$ rectangle (see Figure 14a), adding 24 for the perimeter, and arriving at 44 . One difference between Maisha's use of unit segments for the center and Jill and Ellie's (see Figure 7) was that Maisha's work did not suggest an implicit focus on rows containing equal groups. Lauren disagreed with Maisha and focused instead on equal groups of six dots.

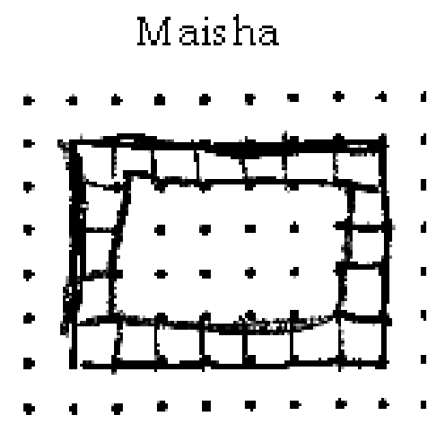

(a)

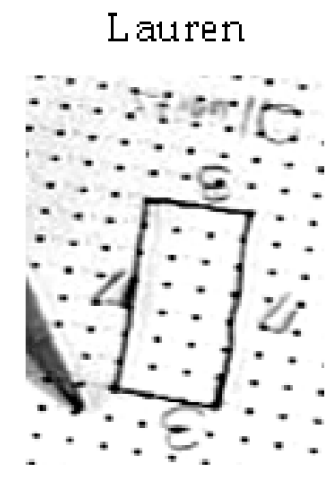

(b)

FIGURE 14 (a) Maisha counted unit segments to calculate area. (b) Lauren counted dots beyond the perimeter. 
In contrast to Jill and Ellie, Maisha and Lauren did not propose a new unit with which to measure areas, but, after I explained that one counts "lines between dots" to determine perimeters and "squares" to determine areas, Maisha consistently counted unit squares to determine totals in the space perspective. Whether she coordinated total numbers of unit squares with products of dimensions during subsequent interviews, however, remained unclear.

Lauren focused on unit segments and unit squares sometimes, but she continually reverted to dots. She first explained that, to determine the area of a $3 \times 7$ rectangle, she "counted each of the lines between the dots." She then counted unit segments along the normative perimeter and got 21. I could not tell why she got 21 instead of 20, but perhaps she erred when counting. Lauren then explained that, to determine perimeter, "you're counting the dots on the outside," and she proceeded to count 28 dots beyond the perimeter of the $3 \times 7$ rectangle (see Figure 14b). When I asked her to determine area once more, she counted the 20 dots along the perimeter. Thus, like Jill and Ellie, Lauren struggled to coordinate her understandings of "inside" and "outside" with corresponding dots.

Given difficulties that especially Lauren had focusing on the space perspective, I did not pursue questions about when rectangles did or did not have to be drawn to scale in much depth. During the third interview, however, I had the students draw a rectangle that was "really long." The width of the rectangle that Lauren drew was approximately three times the height. When I asked if the rectangle could show $7 \times$ 8 , the students first said no, but then Maisha changed her answer to yes. She drew in the $7 \times 8$ array and compared the resulting 56 "rectangle boxes" to 56 square units in a to-scale rectangle. Lauren restated Maisha's explanation, saying that "you're going to end up with the same number of boxes," and traced rows as she counted by seven. These data suggested that Maisha (and possibly Lauren) realized more readily than did Jill and Ellie during Phase II that they could count not-to-scale unit rectangles and so loosened their to-scale criterion more quickly.

Bill and Nick were high-achieving students. Figure 4 shows that one interview with these students occurred in between Mrs. Stuart's fourth and fifth CMW lessons. Their drawn representations and explanations for the first three word problems evidenced connections among multiplication, equal groups, and arrays. Bill and Nick also correctly drew rectangles on dot paper and counted unit segments for dimensions and unit squares for totals. Thus, they coordinated appropriate representational features with dimensions and totals in the space perspective.

Bill recognized more quickly than did Jill and Ellie during Phase II that representing rectangles do not have to be drawn to scale to determine areas of represented rectangles. At one point, he drew the rectangle shown in Figure 15a to show $1 \times 10$ and stated, "It would be really weird to do area like that, one by something, but it would just be 10 .... I mean it's a really bad sketch." Nick questioned Bill's explanation at first, saying, "The units have to be the same amount. You can't just have one that's small and one that's long. But if it is a bad sketch, then yeah you 
a)

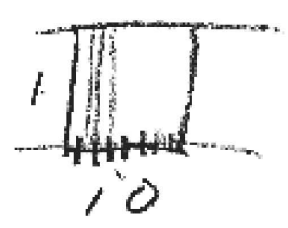

b)

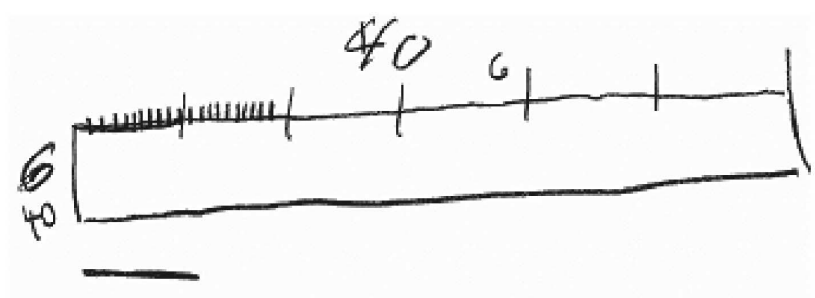

FIGURE 15 (a) Bill's sketch for a $1 \times 10$ rectangle. (b) Bill drew one box for a not-to-scale 40

$\times 6$ rectangle.

could do it." Nick's comment suggested a criterion similar to Ellie's that vertical and horizontal units should be represented by the same length, but he apparently gave less weight to this criterion.

In subsequent discussion, I asked the students to draw a rectangle that showed 6 $\times 40$. Figure $15 \mathrm{~b}$ shows Bill's drawing with the 6 on the vertical and the 40 on the horizontal dimension. I then reversed Bill's labels (see Figure 15b) and asked whether, with new labels, the rectangle could be used first to multiply $6 \times 40$ and then to find the area of a rectangle. Thus, I asked Bill and Nick about two problem-solving goals similar to those that Jill and Ellie had discussed. Bill and Nick responded that if you just wanted to count the boxes to determine area, it would make no difference, and Bill drew one not-to-scale unit below the rectangle (see Figure 15b). Like Maisha, Bill apparently understood more easily than other interview students that counting unit rectangles could determine the area of a represented rectangle.

Rick and Elaine were mid-achieving students. Figure 4 shows that one interview with these students occurred in between Mrs. Stuart's fourth and fifth CMW lessons. Rick's drawn representations and explanations for Problems 2 and 3 evidenced connections among multiplication, equal groups, and arrays, but Elaine appeared to have more trouble. Figures 16a and 16b show Elaine's work for Problems 1 and 2. She explained that her drawn rectangles for Problem 1 showed $5+2=7$, and she may have focused just on the lengths of two adjacent sides. For Problem 2, Elaine drew similar rectangles and said that there were 18 plants in three rows, but she shaded one row of three when I asked her to illustrate her thinking (see Figure 16b). Thus, her verbal explanation and drawn work appeared inconsistent. For 


\section{Problem 1}

(Books)

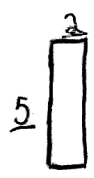

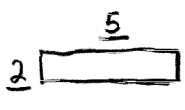

(a)

Problem 2

(Plants)

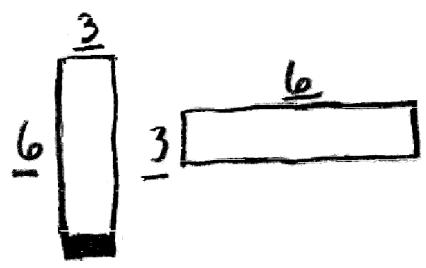

(b)

FIGURE 16 (a) Elaine's diagrams for Problem 1. (b) Elaine's diagrams for Problem 2.

Problem 3, Elaine drew the perimeter of a $4 \times 7$ rectangle, but she stated that she was unsure whether to use addition or multiplication. Rick identified equal groups of unit squares in rows and columns when drawing rectangles on the dot paper, but Elaine had trouble coordinating dimensions and totals in the space perspective. I did not pursue issues of scale with this pair.

\section{DISCUSSION}

As stated at the outset, the study presented here provides an existence proof that the knowledge in pieces perspective can lend insight into learning core elementary mathematics topics, demonstrating that important components are not tied to physics, more advanced mathematics, or the learning of older students. The analytic categories of knowledge for selecting attributes, using representations, and evaluating representations comprise an elaboration of the perspective highlighting how coordination and refinement of multiple knowledge elements can occur as students learn to use representations to solve problems about situations. Contact with past research discussed previously suggests that the categories of knowledge for selecting attributes, using representations, and evaluating representations may be useful when analyzing learning in further domains within and beyond elementary mathematics.

Data on the remaining students suggested that Jill and Ellie were not outliers but did evidence coordination and refinement in more detail than did the other pairs. Maisha and Lauren also focused on dots initially and had trouble coordinating their understandings of "inside" and "outside" with appropriate representational features in both the dot and space perspectives. I could not tell whether Bill, Nick, Rick, or Elaine also focused on dots initially or had trouble with understandings of "inside" and "outside" because their first interviews occurred after Mrs. Stuart's 
second and third lessons. Recall that these lessons were designed to focus students' attention on the space perspective. One reason why Jill and Ellie evidenced more detailed coordination and refinement of knowledge was that they gave higher priority to scale drawings than did Maisha and possibly Lauren, Bill, or Nick. At least Maisha and Nick seemed to understand more readily that they could still count elements in not-to-scale arrays to determine areas.

Readers might ask if the specific results about learning in the study presented here were simply an artifact of developing insufficiently the notion of area as covering at the outset of instruction. Although the study presented here was not initially designed to examine how students might construct areas as coverings, results of past research summarized previously, combined with those of the study presented here, suggest that accessible learning trajectories in the domain of area remains an important focus for future research. Recall that past research has documented cases where students either did, or did not, demonstrate (possibly implicit) understandings of areas as coverings. Past research (Lehrer, 2003; Lehrer et al., 1998; Stephan \& Clements, 2003) also demonstrated that the coordination of multiple ideas related to units can vary from student to student. Although Simon and Blume (1994) hypothesized that students must first understand area as measurable by an array of unit squares before constructing relations between length and area measurements, they did not suggest how students might construct understandings of such arrays. The study presented here provides an existence proof that students can begin to construct areas as arrays of unit squares by refining and coordinating a range of understandings, including those of discrete arrays.

Readers might also ask what was significant about Jill's learning, particularly during Phase II. If she understood areas as arrays of unit squares, would that not suffice given that the instructional goal was to have students use rectangular area representations to understand numeric methods for multidigit multiplication? The answer would be "Yes" if one focused only on the content in the CMW materials, but I argue that changes to "No" if one considers a longer learning trajectory in which students construct relations between representations and situations that afford solutions to problems across topics and domains. Developing flexible relations between representations and problem situations, based on an understanding of what is sufficient for solving a problem, is important for understanding other mathematical representations. For example, Izsák (2003) reported a case in which a pair of eighth-grade students thought that algebraic representations of linear motion should be true for all values of the independent variable, but came to understand that equations (which constrain the independent variable to a unique value) can be solved to determine when specific events occur. I am not suggesting a direct connection between using not-to-scale rectangular representations and being prepared for modeling linear motion with algebraic representations, but rather I am advancing the hypothesis that more explicit attention to relations between representations and situations in the elementary grades might better prepare students for subsequent courses in which more 
complex relations are central. Another direction for future research, therefore, is to search for further opportunities to focus on such relations.

The study presented here extends the small but growing number of results on students' criteria for representations. In particular, the study demonstrates that such criteria can be engaged when students not only design representations, as reported in past research, but also learn to use more schooled representations, although such engagement may be more tacit in this case. This raises the possibility that past research has overlooked the important role that criteria for representations can play, in conjunction with other understandings, when students study still other topics in mathematics and science.

Finally, results of the study presented here suggest that using whiteboards with arrays of dots was neither a complete success nor a failure. The CMW designers and Mrs. Stuart met ahead of time and anticipated that the instructional approach, including the boards, would be accessible to her students. It is fair to say, however, that we assumed her students knew more about area than they did and that we did not adequately account for their past experiences using discrete representations. That Jill, Ellie, Maisha, and Lauren drew heavily on past experience with dots highlights the importance of understanding continuities and discontinuities that students experience as they attend to and use inscriptions to solve problems. Past experiences with arrays of dots both supported and constrained students' coordination of unit segments and squares with dimensions and totals in the space perspective. Moreover, the prevalence of elementary mathematics activities in which students attend to a single feature (e.g., manipulable cubes or drawn objects) suggests that other students with similar experiences might also face challenges when learning to attend adaptively to representational features. More generally, results of the study presented here suggest explicitly identifying similarities and differences between students' past experiences using representations to solve problems and demands of new tasks can be central to successful instructional design.

\section{ACKNOWLEDGMENTS}

The research reported in this article was supported by National Science Foundation (NSF) Grant REC 9806020. The opinions expressed in this article are those of the author and do not necessarily reflect the views of the NSF. I presented a version of this article at the 23rd annual meeting of the North American Chapter of the International Group for the Psychology of Mathematics Education, Snowbird, UT.

I thank Amy Hackenberg, John Olive, Jeremy Roschelle, and anonymous reviewers for commenting on earlier drafts. I also thank Mrs. Stuart and her students for allowing me to be part of their classroom and for participating in this study. 


\section{REFERENCES}

Anghileri, J. (1989). An investigation of young children's understanding of multiplication. Educational Studies in Mathematics, 20, 367-385.

Battista, M. T., Clements, D. H., Arnoff, J. A., Battista, K., \& Borrow, C. V. A. (1998). Students' spatial structuring of 2D arrays of squares. Journal for Research in Mathematics Education, 29, 503-532.

Bell, A., Fischbein, E., \& Greer, B. (1984). Choice of operation in verbal arithmetic problems: The effects of number size, problem structure and context. Educational Studies in Mathematics, 15, 129-147.

Bell, A., Greer, B., Grimison, L., \& Mangan, C. (1989). Children's performance on multiplicative word problems: Elements of a descriptive theory. Journal for Research in Mathematics Education, 20 , 434-449.

Bernard, H. (1994). Research methods in anthropology (2nd ed.). Thousand Oaks, CA: Sage.

Clark, F. B., \& Kamii, C. (1996). Identification of multiplicative thinking in children in grades 1-5. Journal for Research in Mathematics Education, 27, 41-51.

Cobb, P., Stephan, M., McClain, K., \& Gravemeijer, K. (2001). Participating in classroom mathematical practices. The Journal of the Learning Sciences, 10, 113-163.

Confrey, J. (1994). Splitting, similarity, and rate of change: A new approach to multiplication and exponential functions. In G. Harel \& J. Confrey (Eds.), The development of multiplicative reasoning in the learning of mathematics (pp. 291-330). Albany: State University of New York Press.

Confrey, J., \& Scarano, G. H. (1995). Splitting reexamined: Results from a three-year longitudinal study of children in grades three to five. In D. Owens, M. Reed, \& G. Millsaps (Eds.), Proceedings of the Seventeenth Annual Meeting of PME-NA (Vol. 1, pp. 421-426). Columbus: The Ohio State University.

Confrey, J., \& Smith, E. (1994). Exponential functions, rates of change, and the multiplicative unit. Educational Studies in Mathematics, 26, 135-164.

Confrey, J., \& Smith, E. (1995). Splitting, covariation, and their role in the development of exponential functions. Journal for Research in Mathematics Education, 26, 66-86.

Coxford, A., Fey, J., Hirsch, C., Schoen, H., Burrill, G., Hart, E., et al. (1998). Contemporary mathematics in context: A unified approach. Chicago: Everyday Learning.

De Corte, E., Verschaffel, L., \& Van Coillie, V. (1988). Influence of number size, problem structure, and response mode on children's solutions of multiplication word problems. Journal of Mathematical Behavior, 7, 197-216.

diSessa, A. A. (1988). Knowledge in pieces. In G. Forman \& P. Pufall (Eds.), Constuctivism in the computer age (pp. 49-70). Hillsdale, NJ: Lawrence Erlbaum Associates, Inc.

diSessa, A. A. (1993). Toward an epistemology of physics. Cognition and Instruction, 10, 105-225.

diSessa, A. A. (2002). Students' criteria for representational adequacy. In K. Gravemeijer, R. Lehrer, B. van Oers, \& L. Verschaffel (Eds.), Symbolizing, modeling and tool use in mathematics education (pp. 105-129). Dortrecht, The Netherlands: Kluwer Academic.

diSessa, A. A., Elby, A., \& Hammer, D. (2003). J's epistemological stance and strategies. In G. M. Sinatra \& P. R. Pintrich (Eds.), Intentional conceptual change (pp. 237-290). Mahwah, NJ: Lawrence Erlbaum Associates, Inc.

diSessa, A. A., Hammer, D., Sherin, B., \& Kolpakowski, T. (1991). Inventing graphing: Meta-representational expertise in children. Journal of Mathematical Behavior, 10, 117-160.

diSessa, A. A., \& Sherin, B. (2000). Meta-representation: An introduction. Journal of Mathematical Behavior, 19, 385-398.

Fischbein, E., Deri, M., Nello, M. S., \& Marino, M. S. (1985). The role of implicit models in solving verbal problems in multiplication and division. Journal for Research in Mathematics Education, 16, $3-17$.

Fuson, K. C. (in press). Math expressions. Boston: Houghton Mifflin. 
Greer, B. (1992). Multiplication and division as models of situations. In D. Grouws (Ed.), Handbook of research on mathematics teaching and learning (pp. 276-295). New York: Macmillan.

Hammer, D., \& Elby, A. (2002). On the form of a personal epistemology. In B. H. Hofer \& P. R. Pintrich (Eds.), Personal epistemology: The psychology of beliefs about knowledge and knowing (pp. 169-190). Mahwah: NJ: Lawrence Erlbaum Associates, Inc.

Hino, K. (2002). Acquiring new uses of multiplication through classroom teaching: An exploratory study. Journal of Mathematical Behavior, 20, 477-502.

Izsák, A. (2000). Inscribing the winch: Mechanisms by which students develop knowledge structures for representing the physical world with algebra. The Journal of the Learning Sciences, 9, 31-74.

Izsák, A. (2001). Learning multi-digit multiplication by modeling rectangles. In R. Speiser, C. Maher, \& C. Walter (Eds.), Proceedings of the 23rd Annual Meeting of the North American Chapter of the International Group for the Psychology of Mathematics Education (Vol. 1, pp. 187-194). Columbus, OH: ERIC Clearinghouse for Science, Mathematics, and Environmental Education.

Izsák, A. (2003). "We want a statement that is always true": Criteria for good algebraic representations and the development of modeling knowledge. Journal for Research in Mathematics Education, 34, $191-227$.

Izsák, A. (2004a). Students' coordination of knowledge when learning to model physical situations. Cognition and Instruction, 22, 81-128.

Izsák, A. (2004b). Teaching and learning two-digit multiplication: Coordinating analyses of classroom practices and individual student learning. Mathematical Thinking and Learning, 6(1), 37-79.

Izsák, A., \& Fuson, K. C. (2000). Students' understanding and use of multiple representations while learning two-digit multiplication. In M. Fernández (Ed.), Proceedings of the 22nd Annual Meeting of the North American Chapter of the International Group for the Psychology of Mathematics Education (Vol. 2, pp. 715-721). Columbus, OH: ERIC Clearinghouse for Science, Mathematics, and Environmental Education.

Kouba, V. L. (1989). Children's solution strategies for equivalent set multiplication and division word problems. Journal for Research in Mathematics Education, 20, 147-158.

Lampert, M. (1986a). Knowing, doing, and teaching multiplication. Cognition and Instruction, 3, $305-342$.

Lampert, M. (1986b). Teaching multiplication. Journal of Mathematical Behavior, 5, 241-280.

Lappan, G., Fey, J. T., Fitzgerald, W., Friel, S. N., \& Phillips, E. D. (2002). Connected mathematics series. Glenview, IL: Prentice Hall.

Lehrer, R. (2003). Developing understanding of measurement. In J. Kilpatrick, W. G. Martin, \& D. Shifter (Eds.), A research companion to principles and standards for school mathematics (pp. 179-193). Reston, VA: National Council of Teachers of Mathematics.

Lehrer, R., Jenkins, M., \& Osana, H. (1998). Longitudinal study of children's reasoning about space and geometry. In R. Lehrer \& D. Chazan (Eds.), Designing learning environments for developing understandings of geometry and space (pp. 137-167). Mahwah, NJ: Lawrence Erlbaum Associates, Inc.

Lobato, J., Ellis, A., \& Muñoz, R. (2003). How "focusing phenomena" in the instructional environment support individual students' generalizations. Mathematical Thinking and Learning, 5(1), 1-36.

Lobato, J., \& Siebert, D. (2002). Quantitative reasoning in a reconceived view of transfer. Journal of Mathematical Behavior, 21, 87-116.

Mechmandarov, I. (1987). The role of dimensional analysis in teaching multiplicative word problems. Unpublished manuscript, Center for Educational Technology, Tel Aviv, Israel.

Meira, L. (1995). The microevolution of mathematical representations in children's activities. Cognition and Instruction, 13, 269-313.

Monk, S., \& Nemirovsky, R. (1994). The case of Dan: Student construction of a functional situation through visual attributes. In A. Schoenfeld, E. Dubinsky, \& J. Kaput (Eds.), Research in collegiate mathematics education (Vol. 1, pp. 139-168). Washington, DC: American Mathematics Association. 
Moschkovich, J. (1998). Resources for refining mathematical conceptions: Case studies in learning about linear functions. The Journal of the Learning Sciences, 7, 209-237.

Mulligan, J. T., \& Mitchelmore, M. C. (1997). Young children's intuitive models of multiplication and division. Journal for Research in Mathematics Education, 28, 309-330.

National Council of Teachers of Mathematics. (1989). Curriculum and evaluation standards for school mathematics. Reston, VA: Author.

National Council of Teachers of Mathematics. (2000). Principles and standards for school mathematics. Reston, VA: Author.

Nemirovsky, R. (1994). On ways of symbolizing: The case of Laura and the velocity sign. Journal of Mathematical Behavior, 13, 389-422.

Nesher, P. (1988). Multiplicative school word problems: Theoretical approaches and empirical findings. In J. Hiebert \& M. Behr (Eds.), Number concepts and operations in middle grades (pp. 19-40). Reston, VA: National Council of Teachers of Mathematics.

Nesher, P. (1992). Solving multiplication word problems. In G. Leinhardt, R. Putnam, \& R. A. Hattrup (Eds.), Analysis of arithmetic for mathematics teaching (pp. 189-219). Hillsdale, NJ: Lawrence Erlbaum Associates, Inc.

Outhred, L. N., \& Mitchelmore, M. C. (2000). Young children's intuitive understanding of rectangular area measurement. Journal for Research in Mathematics Education, 31, 144-167.

Peled, I., \& Nesher, P. (1988). What children tell us about multiplication word problems. Journal of Mathematical Behavior, 7, 239-262.

Reynolds, A., \& Wheatley, G. H. (1996). Elementary students' construction and coordination of units in an area setting. Journal for Research in Mathematics Education, 27, 564-581.

Roschelle, J. (1998). Beyond romantic and skeptic: A microanalysis of conceptual change in kinematics. International Journal of Science Education, 20, 1025-1042.

Scarano, G. H., \& Confrey, J. (1996, April). Results from a three-year longitudinal teaching experiment designed to investigate splitting, ratio and proportion. Paper presented at the annual meeting of the American Educational Research Association, New York.

Schmidt, S., \& Weiser, W. (1995). Semantic structures of one-step word problems involving multiplication or division. Educational Studies in Mathematics, 28, 55-72.

Schoenfeld, A. H., Smith, J., \& Arcavi, A. (1993). Learning: The microgenetic analysis of one student's evolving understanding of a complex subject matter domain. In R. Glaser (Ed.), Advances in instructional psychology (Vol. 4, pp. 55-175). Hillsdale, NJ: Lawrence Erlbaum Associates, Inc.

Schwartz, J. (1988). Intensive quantity and referent transforming arithmetic operations. In J. Hiebert \& M. Behr (Eds.), Number concepts and operations in the middle grades (pp. 41-52). Reston, VA: National Council of Teachers of Mathematics.

Sherin, B. (2001). How students understand physics equations. Cognition and Instruction, 19, 479-541.

Simon, M., \& Blume, G. (1994). Building and understanding multiplicative relationships: A study of prospective elementary teachers. Journal for Research in Mathematics Education, 25, $472-494$.

Smith, J. P. (1995). Competent reasoning with rational numbers. Cognition and Instruction, 13, $3-50$.

Smith, J. P., diSessa, A. A., \& Roschelle, J. (1993). Misconceptions reconceived: A constructivist analysis of knowledge in transition. The Journal of the Learning Sciences, 3, 115-163.

Steffe, L. P. (1988). Children's construction of number sequences and multiplying schemes. In J. Hiebert \& M. Behr (Eds.), Number concepts and operations in middle grades (pp. 119-140). Reston, VA: National Council of Teachers of Mathematics.

Steffe, L. P. (1994). Children's multiplying schemes. In G. Harel \& J. Confrey (Eds.), The development of multiplicative reasoning in the learning of mathematics (pp. 3-39). Albany: State University of New York Press. 
Stephan, M., \& Clements, D. (2003). Linear, area, and time measurement in prekindergarten to grade 2. In D. Clements \& G. Bright (Eds.), Learning and teaching measurement (2003 yearbook) (pp. 3-16). Reston, VA: National Council of Teachers of Mathematics.

Treffers, A. (1987). Integrated column arithmetic according to progressive schematisation. Educational Studies in Mathematics, 18, 125-145.

The University of Chicago School Mathematics Project. (1995). Everyday mathematics. Evanston, IL: Everyday Learning Corporation.

Vergnaud, G. (1983). Multiplicative structures. In R. Lesh \& M. Landau (Eds.), Acquisition of mathematics concepts and processes (pp. 127-174). New York: Academic.

Vergnaud, G. (1988). Multiplicative structures. In J. Hiebert \& M. Behr (Eds.), Number concepts and operations in middle grades (pp. 141-161). Reston, VA: National Council of Teachers of Mathematics.

Wagner, J. F. (2003). The construction of similarity: Context sensitivity and the transfer of mathematical knowledge. Unpublished doctoral dissertation, University of California, Berkeley. 
Copyright of Journal of the Learning Sciences is the property of Lawrence Erlbaum Associates and its content may not be copied or emailed to multiple sites or posted to a listserv without the copyright holder's express written permission. However, users may print, download, or email articles for individual use. 